\title{
From polybenzimidazoles to polybenzimidazoliums and polybenzimidazolides
}

\author{
Aili, David; Yang, Jingshuai; Jankova, Katja Jankova; Henkensmeier, Dirk; Li, Qingfeng
}

Published in:

Journal of Materials Chemistry A

Link to article, DOI:

$10.1039 / \mathrm{d} 0 \mathrm{ta} 01788 \mathrm{~d}$

Publication date:

2020

Document Version

Peer reviewed version

Link back to DTU Orbit

Citation (APA):

Aili, D., Yang, J., Jankova, K. J., Henkensmeier, D., \& Li, Q. (2020). From polybenzimidazoles to polybenzimidazoliums and polybenzimidazolides. Journal of Materials Chemistry A, 8(26), 12854-12886. https://doi.org/10.1039/d0ta01788d

\section{General rights}

Copyright and moral rights for the publications made accessible in the public portal are retained by the authors and/or other copyright owners and it is a condition of accessing publications that users recognise and abide by the legal requirements associated with these rights.

- Users may download and print one copy of any publication from the public portal for the purpose of private study or research.

- You may not further distribute the material or use it for any profit-making activity or commercial gain

- You may freely distribute the URL identifying the publication in the public portal

If you believe that this document breaches copyright please contact us providing details, and we will remove access to the work immediately and investigate your claim 


\title{
From polybenzimidazoles to polybenzimidazoliums and polybenzimidazolides
}

David Aili, ${ }^{\mathrm{a},}$, Jingshuai Yang ${ }^{\mathrm{b},{ }^{*}}$, Katja Jankova ${ }^{\mathrm{a}, \mathrm{c}}$, Dirk Henkensmeier ${ }^{\mathrm{d}, \mathrm{e}, \mathrm{f}}$, Qingfeng Li $^{\mathrm{a}}$

a Department of Energy Conversion and Storage, Technical University of Denmark, Fysikvej 310, 2800 Kgs. Lyngby, Denmark, "Corresponding author (E-mail: larda@dtu.dk)

b Department of Chemistry, College of Sciences, Northeastern University, Shenyang 110819, China, ${ }^{*}$ Corresponding author (E-mail: yjs@mail.neu.edu.cn)

c Soft Materials Chemistry, Institute for Materials Chemistry and Engineering, Kyushu University, Build. CE41, 744 Motooka Nishi-ku, Fukuoka, 819-0395, Japan

d Center for Hydrogen and Fuel Cell Research, Korea Institute of Science and Technology, Hwarangno 14-gil 5, Seongbuk-gu, Seoul 02792, Korea

e Division of Energy \& Environment Technology, KIST School, University of Science and Technology, Seongbuk-gu, Seoul, 02792, Republic of Korea

f Green School, Korea University, Seongbukgu, Seoul, 02841, Republic of Korea

\begin{abstract}
The polybenzimidazoles represent a large family of high-performance polymers containing benzimidazole groups as part of the structural repeat unit. New application areas in electrochemical cells and separation processes have emerged during the last two decades, which has been a major driver for the tremendous development of new polybenzimidazole chemistries and materials in recent years. This comprehensive treatise is devoted to an investigation of the structural scope of polybenzimidazole derivatives, polybenzimidazole modifications and the acid-base behavior of the resulting materials. Advantages and limitations of different synthetic procedures and pathways are analyzed, with focus on homogeneous solution polymerization. The discussion extends to the solution properties of the obtained polybenzimidazoles and the challenges that are faced in connection to molecular weight determination and processing. Methods for polybenzimidazole
\end{abstract}


grafting or crosslinking, in particular by $N$-coupling, are reviewed and successful polymer blend strategies are identified.

The amphoteric nature of the benzimidazole groups further enriches the chemistry of the polybenzimidazoles, as cationic or anionic ionenes are obtained depending on the $\mathrm{pH}$. In the presence of protic acids, such as phosphoric acid, cationic ionenes in the form of protic polybenzimidazoliums are obtained. The acid sorption dramatically changes the physicochemical properties of the material, which is discussed and analyzed in detail. Cationic ionenes are also obtained by full $N$-alkylation of a polybenzimidazole to the corresponding poly(dialkyl benzimidazolium), which has been intensively explored as a new direction in the field of anion exchange membranes recently. In the higher end of the $\mathrm{pH}$ scale in aqueous hydroxide solutions, anionic ionenes in the form of polybenzimidazolides are obtained as a result of the deprotonation of the benzimidazole groups. The ionization of the polymer results in dramatically changed physicochemical properties as compared with the pristine material, which is described and discussed.

From a technological point of view, performance and stability targets continue to motivate further research and development of new polybenzimidazole chemistries and energy materials. The overall aim of this review is therefore to identify challenges and opportunities in this area from synthetic chemistry and materials science perspectives to serve as a solid basis for further development prospects.

\section{Contents}

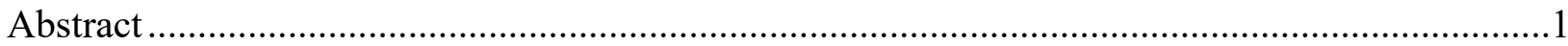

List of abbreviations Error! Bookmark not defined.

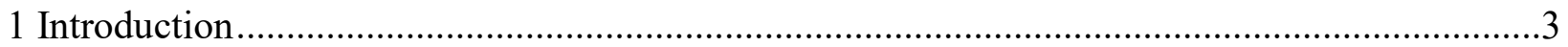

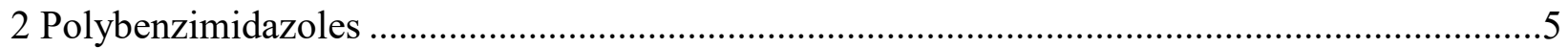

2.1 Structural scope from homogeneous solution polymerization ........................................5

2.2 Solubility, solution properties and molecular weight determination.................................23

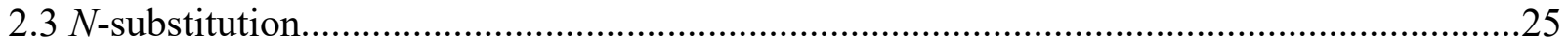


2.4 Crosslinked and branched structures

2.5 Polymer blends and interpenetrating polymer networks

2.6 Solid state properties and stability 30

3 Protic polybenzimidazoliums. .31

3.1 Interaction with protic acids and acid sorption. .31

3.2 Thermal, chemical and dimensional stability .34

3.3 Ion conductivity and transport characteristics .36

4 Poly(dialkyl benzimidazolium) .38

5 Polybenzimidazolides 42

6 Concluding remarks and prospects for further development. .46

Acknowledgement

References

\section{Introduction}

Polymers with benzimidazole groups as a part of the structural repeat unit comprise a large family of engineering plastics known as polybenzimidazole (PBI). ${ }^{1}$ The PBIs can be partly or fully aromatic, and are typically characterized by outstanding thermo-mechanical properties. This makes them particularly suitable for various demanding high-temperature applications in the form of fibers or coatings, like protective garment for fire fighters etc., as reviewed by $\mathrm{Neuse}^{2}$ and Chung. ${ }^{3}$

During the last two decades, the application scope of PBIs has broadened significantly to extend far beyond the high-performance structural materials, as shown in Figure 1. In particular, functionalized PBI derivatives have been widely explored as electrolyte systems and separators in electrochemical devices such as acidic ${ }^{4,5}$ or alkaline ${ }^{6,7}$ fuel cells, water ${ }^{8-10}$ or sulfur dioxide ${ }^{11}$ electrolyzers, flow batteries, ${ }^{12-19}$ lithium metal $^{20}$ or ion $^{21}$ batteries, hydrogen sensors, ${ }^{22-24}$ actuators $^{25}$ as well as electrochemical hydrogen purification ${ }^{26,27}$ and compression ${ }^{28,29}$ units. 
Furthermore, derivatives of PBI are emerging as promising base materials for various demanding gas- $^{30-34}$ and liquid ${ }^{35,36}$ separations.
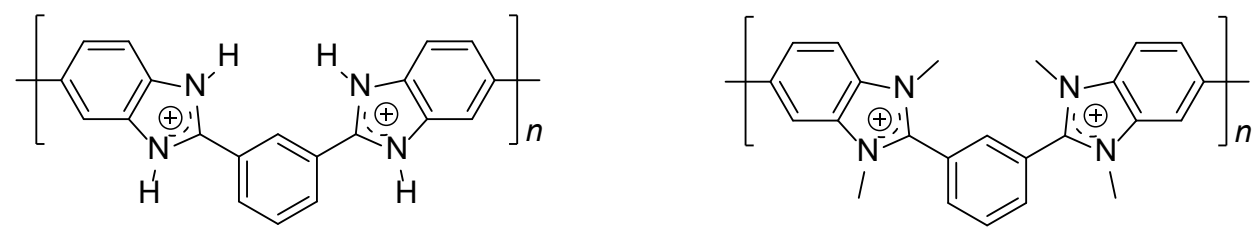

Protic polybenzimidazoliums

- Fuel cells

- Hydrogen pumping

- Gas separation

- Flow batteries
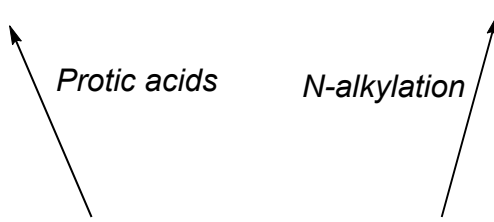

Poly(dialkyl benzimidazoliums)

- Fuel cells

- Water electrolysis

- Flow batteries

- Actuators<smiles>Cc1ccc2[nH]c(-c3cccc(-c4nc5ccc(C(C)(C)C)cc5[nH]4)c3)nc2c1</smiles>

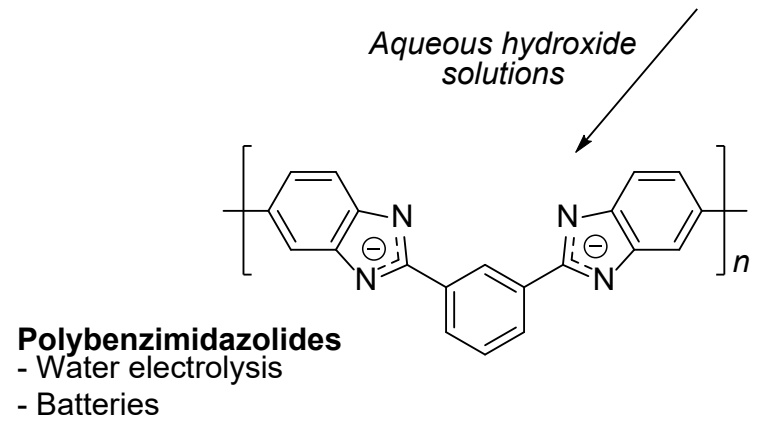

Polybenzimidazoles

- Protective garment for fire fighters

- Aircraft wall fabrics

- Filters

- Gas and liquid separations

- Astronaut space suits

Figure 1 Examples of applications for polybenzimidazole and the corresponding polybenzimidazoliums and polybenzimidazolides.

The inherent functionality of the PBIs stems from the amphoteric nature of the benzimidazole groups. They react according to fundamental Brønsted acid-base chemistry to form cationic ionenes as protic polybenzimidazoliums in acidic environment or anionic ionenes as polybenzimidazolides under alkaline conditions. The ionization of the polymer backbone is often accompanied by a substantial uptake of excess acid/base as well as water, depending on the composition of the solution in which the solid polymer is equilibrated. It produces materials that combine the mechanical robustness and gas tightness of the polymer with the conductive properties of the absorbed acid or base. Alternatively, $N$-alkylation or arylation of PBIs produces anion exchange materials that selectively conduct anions in the presence of water. 
The development of new polybenzimidazole chemistries was intensified following the pioneering work by Wainright et al., ${ }^{37}$ who developed an electrolyte system based on phosphoric acid doped PBI for fuel cells operating at temperatures up to $200{ }^{\circ} \mathrm{C}$. The literature in this field is voluminous and several reviews provide a good overview of the field from a technological point of view together with interesting perspectives and prospects for further technological development. $^{38-47}$

The aim of this review is to provide a comprehensive overview of the scope of PBI chemistries available in the scientific literature. The polymers are discussed in light of synthetic procedures and structural variations and their corresponding solution properties. It extends to filmforming properties and their interaction with acids and bases as polybenzimidazoliums and polybenzimidazolides, which is critically discussed in light of their physicochemical characteristics with special emphasis on ion conductivity behavior in the solid state.

\section{Polybenzimidazoles}

\subsection{Structural scope from homogeneous solution polymerization}

The first polybenzimidazoles in the fully aromatic form were reported by Vogel and Marvel ${ }^{1,48}$ in the early 1960s. The synthesis was based on a two-stage melt condensation polymerization using aromatic diamines and dicarboxylic acid derivatives (diphenyl esters) as monomers. A few years later, an alternative homogeneous solution polymerization process was reported by Iwakura, ${ }^{49}$ who used polyphosphoric acid (PPA) as the polycondensation solvent. A typical procedure involves dissolution of the monomers in PPA at solid contents typically ranging from 3-5 wt $\%$, whereafter the temperature is gradually increased to around $170-230^{\circ} \mathrm{C}$ during a few hours up to some days depending on the desired degree of polymerization. The water generated as a byproduct from the polycondensation reaction is consumed by the hydrolytic splitting of PPA, and the efficient removal of the formed water promotes the polymerization process in line with Le Chatelier's principle. The polymer can subsequently be isolated by precipitation in water followed by extensive washing with water and dilute aqueous base (e.g. carbonate solution) to neutralize and wash out the phosphoric acid residuals. The multiple-step batch procedure at low solid contents in combination with time-consuming work-up makes the process unpractical and expensive in a larger industrial processes, but it remains widely used for the preparation of PBIs on the laboratory scale. 
The synthetic procedure for the structurally most simple derivative in the PBI family, poly(2,5-benzimidazole) (AB-PBI), obtained by homopolymerization of 3,4-diaminobenzoic acid in PPA, is schematically illustrated in Scheme 1 (top). ${ }^{50-55}$

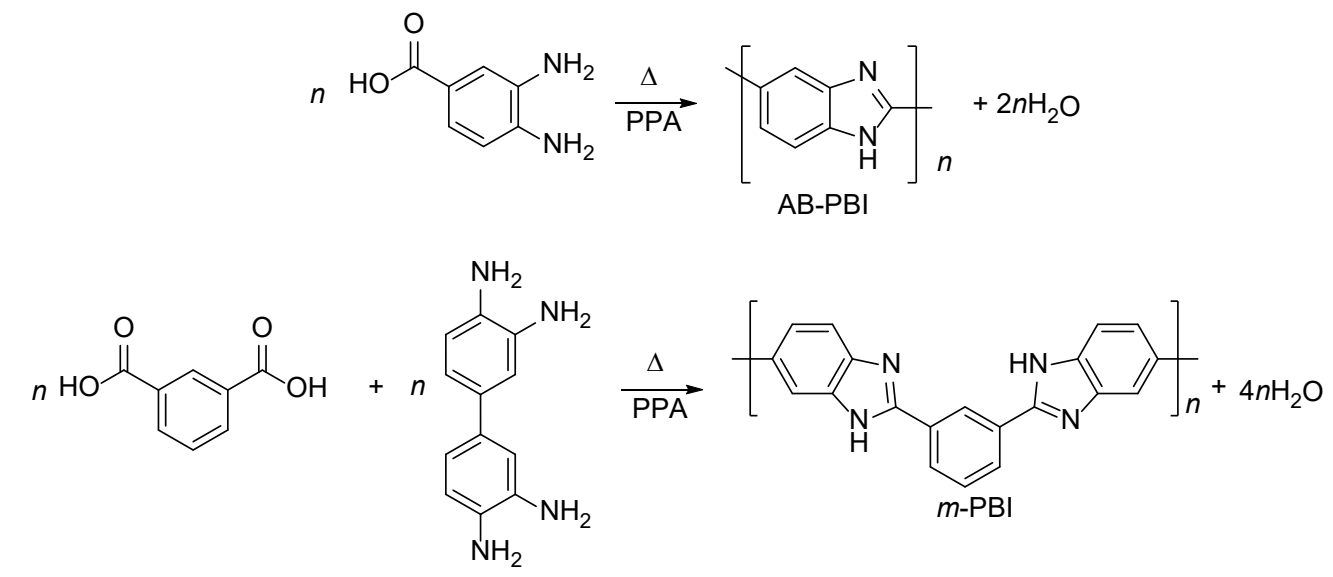

Scheme 1 Synthesis of AB-PBI (top) and $m$-PBI (bottom).

The use of a single monomer for the synthesis of AB-PBI makes stoichiometric control irrelevant as long as pure monomer is used. High-molecular weight polymer with an inherent viscosity of 1.4-2.5 $\mathrm{dL} \mathrm{g}^{-1}$ (measured at $30{ }^{\circ} \mathrm{C}$ in $96 \% \mathrm{H}_{2} \mathrm{SO}_{4}$ at $0.5 \mathrm{~g} \mathrm{dL}^{-1}$ ) can be obtained after $5 \mathrm{~h}$ at $200{ }^{\circ} \mathrm{C}$ in PPA at a solid content of $6 \% .^{50,56}$

The monomer used for AB-PBI synthesis is readily available on a commercial basis and the polymer shows superior physicochemical properties in terms of e.g. mechanical strength and chemical resistance. However, AB-PBI is practically insoluble in common organic solvents and is not widely used due to the severe processing challenges that it imposes.

One way to improve the organosolubility is to introduce a flexible $m$-phenylene linkage between the benzimidazole groups in the backbone structure. Such a PBI derivative is accessible via the AA-BB approach by polycondensation of isophthalic acid and 3,3'-diaminobenzidine (DAB) and yields poly(2,2'-( $m$-phenylene)-5,5'-bibenzimidazole) ( $m$-PBI or PBI), as shown in Scheme 1 (bottom). Network polymers are obtained if a trifunctional carboxylic acid derivative is used, ${ }^{57,58}$ but the limited solubility of the network polymers results in processing challenges. ${ }^{59}$

The freebase of DAB is susceptible to oxidation under ambient conditions and must therefore be handled and stored with great care to ensure the high purity needed to obtain welldefined polymers with high degrees of polymerization. ${ }^{60}$ The tetrahydrochloride salt form of DAB 
shows better stability than the freebase and produces well defined $m$-PBI with high inherent viscosities of $1.5 \mathrm{dL} \mathrm{g}^{-1}$ (measured at $30{ }^{\circ} \mathrm{C}$ in $96 \% \mathrm{H}_{2} \mathrm{SO}_{4}$ at $0.5 \mathrm{~g} \mathrm{dL}^{-1}$ ). ${ }^{61}$ Additional drying agents, such as phosphorous pentoxide or triphenyl phosphite, to further promote the polycondensation reaction has not proven to be particularly effective in terms of reaching higher degrees of polymerization at shorter reaction times and/or lower temperatures. ${ }^{62}$

As summarized in Table 1 (Entry 1), a few alternative synthetic methods for the preparation of $m$-PBI have been reported. For example, microwave irradiation can be employed to shorten the polycondensation time in PPA. ${ }^{63,64}$ A mixture of methanesulfonic acid (MSA) and phosphourous pentoxide $\left(\mathrm{P}_{2} \mathrm{O}_{5}\right)$, commonly referred to as the Eaton's reagent, ${ }^{65}$ is also widely used and produces $m$-PBI at significantly lower temperatures and shorter reaction times than in PPA. ${ }^{66,67}$ The early work by Ueda et al. ${ }^{66}$ showed that higher degrees of polymerization could be obtained in Eaton's reagent when electron rich ether containing dicarboxylic acids are used instead of isophtalic acid. Direct routes to polybenzimidazoles in common organic solvents are scarce, but Higgins and Marvel ${ }^{68}$ obtained $m$-PBI from homogeneous solution polymerization in DMAc by converting the dicarboxylic acid monomer to the corresponding isophthalaldehyde bisulfite adduct prior to the polycondensation with DAB. The phthalaldehyde bisulfite adduct slowly liberates the original aldehyde groups, which mitigates the side reactions and cross-couplings that are observed when the dialdehydes are used directly. The methodology was further developed and optimized by Fishel et al.$^{69}$ and Kim et al., ${ }^{70}$ yielding high molecular weight $m$-PBI at solid contents as high as $18-22 \%$ directly in DMAc. Furthermore, refluxing sulfolane or phenyl sulfone or eutectic mixtures of $\mathrm{LiCl} / \mathrm{KCl}$ have also been reported as solvent systems for the preparation of $m-\mathrm{PBI}$ at temperatures close to $400{ }^{\circ} \mathrm{C}^{71,72}$ The latter produced $m$-PBI at intermediate molecular weight, but it could also produce well-defined polymers that have not been obtained using other solvent systems from more complex spirofluorene carboxylic acid monomers.

The structural scope of PBIs that are available from homogenous solution polymerization by varying the dicarboxylic acid is extensive, as summarized in Table 1 . The process generally produces high molecular weight PBIs within a few hours up to a couple of days and works well for the polycondensation between $\mathrm{DAB}$ and various aromatic, heteroaromatic and halogenated dicarboxylic acids. In addition to isophthalic acid, which yields $m$-PBI, these include commercially available dicarboxylic acids such as terephthalic acid (Table 1; Entry 2), 4,4'-sulfonyldibenzoic 
acid (Entry 12), 2,2'-bis(4-carboxyphenyl)hexafluoropropane (Table 1; Entry 42) as well as various pyridine dicarboxylic acids (Table 1; Entry 19-27).

Many PBIs reported in the literature are not accessible via the PPA route due to poor solubility of the dicarboxylic acid ${ }^{31,73-75}$ or due to pronounced side-reactions in hot PPA. ${ }^{31}$ These can instead be obtained from polycondensation in Eaton's reagent. As shown in Table 1, the use of Eaton's reagent seems to be the only known route to polybenzimidazoles derived from larger dicarboxylic acids, particularly various arylene ethers (Table 1; Entry 14-18, 26, 41, 45, 47). ${ }^{31}, 66$, ${ }^{75-78}$ As discussed above, electron rich dicarboxylic acid also seem to have higher reactivity in Eaton's reagent than electron deficient dicarboxylic acids, which results in a higher degree of polymerization ${ }^{66}$ Like in the PPA system, microwave heating has been reported to shorten reaction times in Eaton's reagent as well. ${ }^{79}$

More exotic structures based on e.g. carborane ${ }^{80}$ or metallocene ${ }^{81,82}$ links have also been reported in the literature, but the structures are omitted in the table.

Table 1 Main-chain homopolymer derivatives of polybenzimidazoles obtained from homogeneous solution polymerization of $\mathrm{DAB}$ and various dicarboxylic acids. The temperatures indicated in the table are the maximum temperatures reached during the polycondensation, and the indicated times represent the total duration of the process. The reader is referred to the original reference for full synthetic details and information about yields and degrees of polymerization reached.

\begin{tabular}{|l|l|l|l|}
\hline \multicolumn{2}{|l|}{} & Conditions & Ref \\
\hline Entry \# & $\mathbf{R}$ & PPA, $170-220^{\circ} \mathrm{C}, 4-20 \mathrm{~h}$ & $49,61,83-86$ \\
\hline Aromatic & $\begin{array}{l}\text { PPA, } 170{ }^{\circ} \mathrm{C}, 3 \mathrm{~h}, \\
\text { microwave }\end{array}$ & 63,64 \\
\hline 1 & &
\end{tabular}




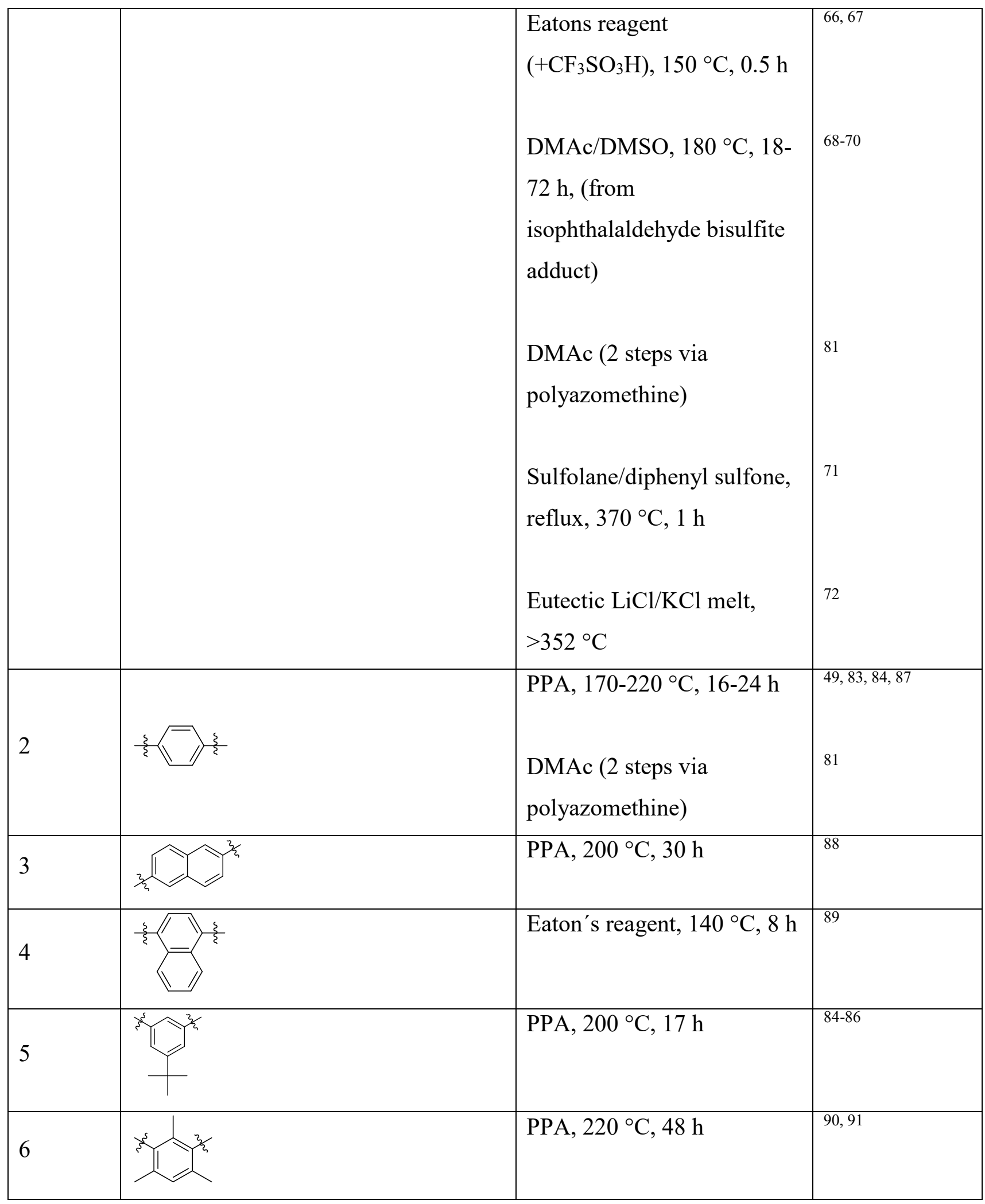




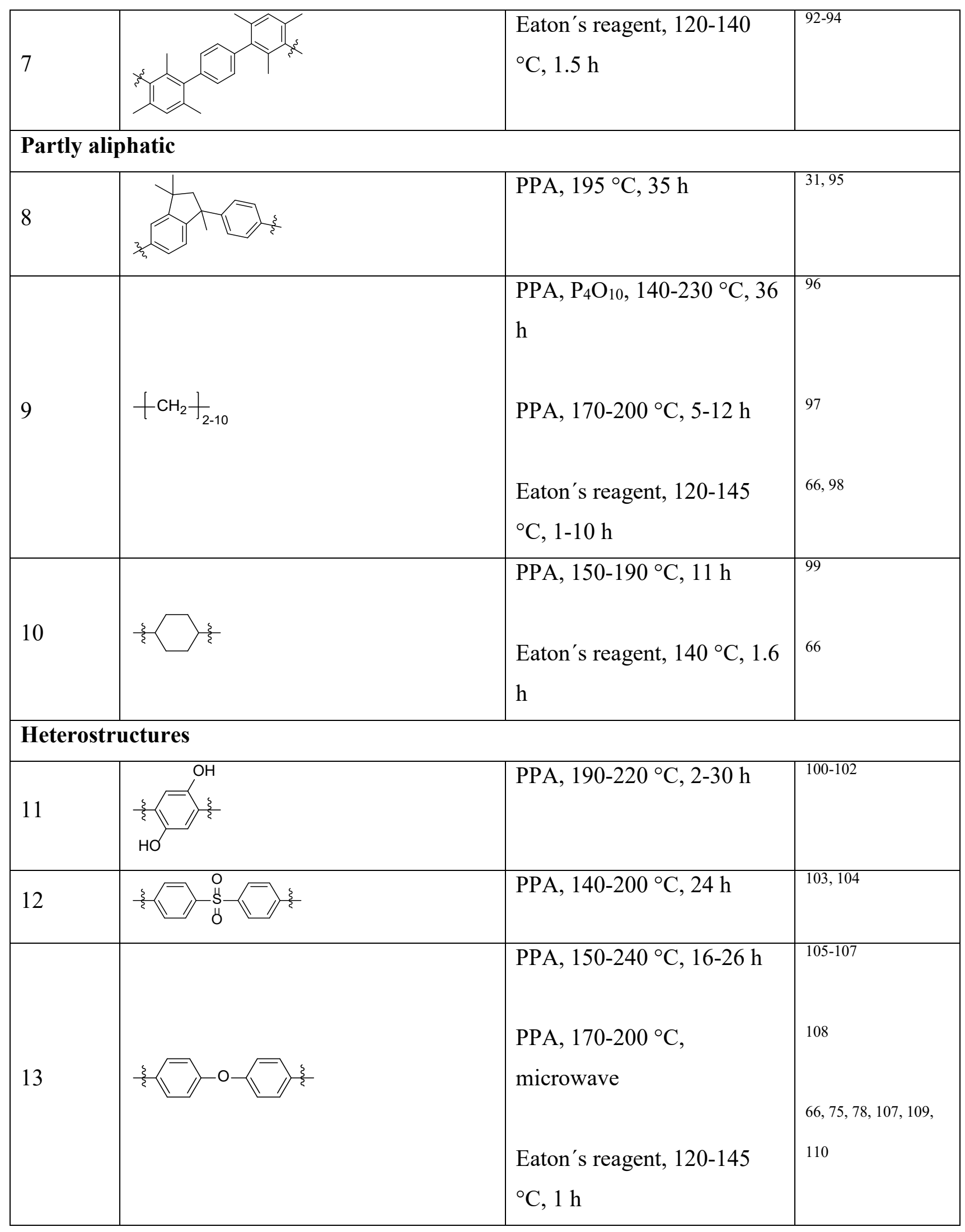




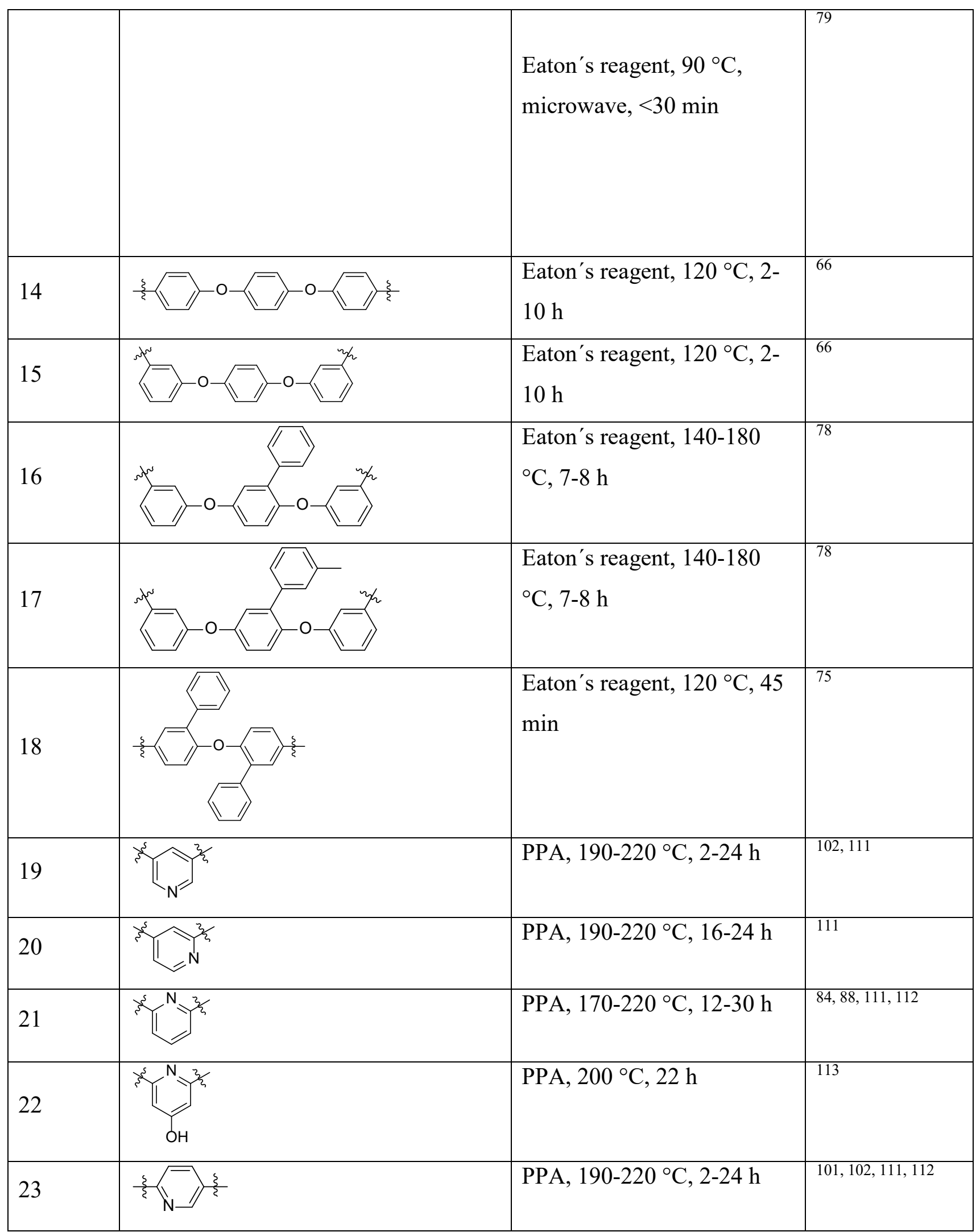




\begin{tabular}{|c|c|c|c|}
\hline 24 & $\xi \sqrt{n} N^{-}$ & PPA, $200^{\circ} \mathrm{C}$ & 112 \\
\hline 25 & & $\mathrm{PPA}, 200^{\circ} \mathrm{C}, 12 \mathrm{~h}$ & 114 \\
\hline 26 & & $\begin{array}{l}\text { Eaton's reagent, } 80-140^{\circ} \mathrm{C} \text {, } \\
8 \mathrm{~h}\end{array}$ & 77 \\
\hline 27 & & $\begin{array}{l}\mathrm{PPA}, 90-200{ }^{\circ} \mathrm{C}, 5 \mathrm{~h}, \\
\text { microwave }\end{array}$ & 115 \\
\hline 28 & & $\mathrm{PPA}, 140-220^{\circ} \mathrm{C}, 13 \mathrm{~h}$ & 54 \\
\hline & & $\mathrm{PPA}, 240^{\circ} \mathrm{C}, 12 \mathrm{~h}$ & 116,117 \\
\hline 30 & & PPA, $140-220^{\circ} \mathrm{C}, 24 \mathrm{~h}$ & \\
\hline 31 & है। & PPA, $200-220^{\circ} \mathrm{C}, 26 \mathrm{~h}$ & 112,119 \\
\hline & & PPA, $170-200^{\circ} \mathrm{C}, 14 \mathrm{~h}$ & 120 \\
\hline 33 & & PPA, $140-220^{\circ} \mathrm{C}, 48 \mathrm{~h}$ & 121 \\
\hline 34 & & PPA, $140-190^{\circ} \mathrm{C}, 22 \mathrm{~h}$ & 122 \\
\hline 35 & & $\mathrm{PPA}, 170-200^{\circ} \mathrm{C}, 24 \mathrm{~h}$ & 123 \\
\hline
\end{tabular}




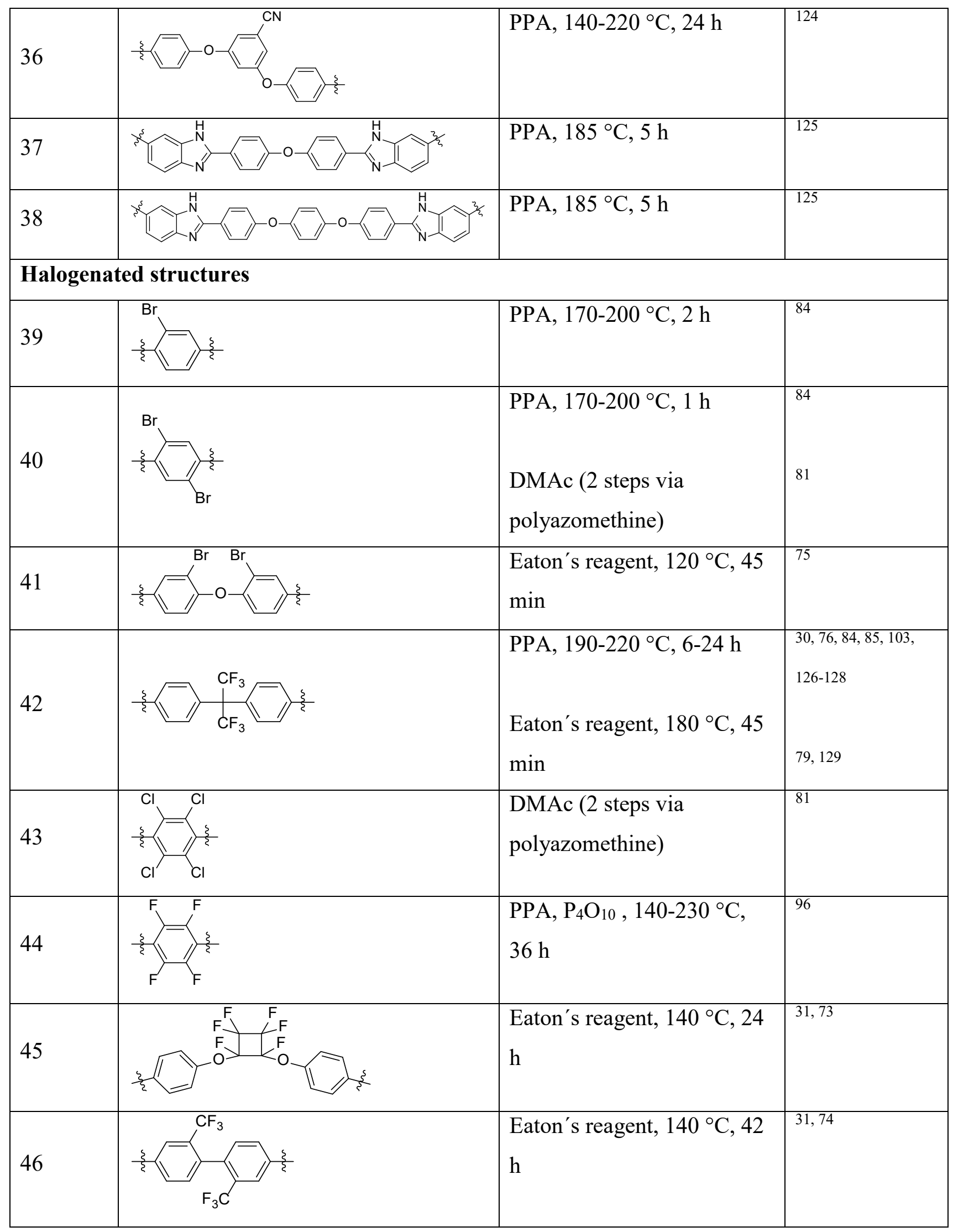




\begin{tabular}{|l|l|l|l|}
\hline & & \\
\hline
\end{tabular}

Varying the dicarboxylic acid is by far the most thoroughly explored approach to extend the structural scope of PBI homopolymers from homogeneous solution polymerization. This is mainly due to the commercial availability of vastly different dicarboxylic acid chemistries, but structural modifications of the tetraamine have been reported as well. However, this typically involves a bottom-up synthesis of the tetraamine monomer and obtaining sufficient quality and quantity for further polymerization is often challenging. As shown in Table 2 (Entry 1-5), a series of PBIs derived from commercially available 3,3',4,4'-tetraaminodiphenyl ether and different dicarboxylic acids were obtained by polycondensation in DMAc in a 2 step procedure. ${ }^{81}$ Similarly, a series of 2,6-bis(3',4'-diaminophenyl)-4-phenylpyridine (synthesized on $100 \mathrm{~g}$ scale in 5 steps) derived PBIs were obtained from a facile polycondensation with different dicarboxylic acids in PPA at 210 ${ }^{\circ} \mathrm{C}$ over 24 h (Table 2; Entry 10-15). ${ }^{134}$ One of the few organic solvent based synthetic protocols of polybenzimidazoles is the polycondensation of diphenyl isophthalate and 3,3',4,4'tetraaminodiphenyl ether or 3,3',4,4'-tetraaminobenzophenone (Table 2; Entry 16 and 17, respectively). ${ }^{71}$

Table 2 Main-chain homopolymer derivatives of polybenzimidazoles obtained from homogeneous solution polymerization of various tetraamines and dicarboxylic acids. The indicated temperatures indicated in the table are the maximum temperatures reached during the 
polycondensation, and the indicated times represent the total duration of the process. The reader is referred to the original reference for full synthetic conditions.

\begin{tabular}{|c|c|c|c|c|}
\hline Entry \# & $\mathbf{R}_{1}$ & $\mathbf{R}_{2}$ & Conditions & Ref \\
\hline 1 & $\frac{\xi}{2} 0 \frac{\xi}{2}$ & & $\begin{array}{l}\text { DMAc (2 steps via } \\
\text { polyazomethine) }\end{array}$ & 81 \\
\hline 2 & $\frac{\xi}{2} 0 \frac{\xi}{\xi}$ & & $\begin{array}{l}\text { DMAc (2 steps via } \\
\text { polyazomethine) }\end{array}$ & 81 \\
\hline 4 & 多O多 & & $\begin{array}{l}\text { DMAc (2 steps via } \\
\text { polyazomethine) }\end{array}$ & 81 \\
\hline 5 & $\frac{\xi}{2} 0 \frac{\xi}{\xi}$ & & $\begin{array}{l}\text { DMAc (2 steps via } \\
\text { polyazomethine) }\end{array}$ & 81 \\
\hline 6 & $\frac{\xi}{2} 0 \frac{\xi}{\xi}$ & & $\begin{array}{l}\text { Polymer from commercial } \\
\text { supplier. Synthetic details } \\
\text { not provided }\end{array}$ & $135-137$ \\
\hline 7 & $\sum_{2}^{0} \int_{0}^{0}$ & & $\begin{array}{l}\text { Eaton's reagent, } 148^{\circ} \mathrm{C}, \\
24 \mathrm{~h}\end{array}$ & 138 \\
\hline 8 & $\frac{3}{2} \int_{0}^{0} \frac{\xi}{2}$ & & $\begin{array}{l}\text { Eaton's reagent, } 148^{\circ} \mathrm{C}, \\
24 \mathrm{~h}\end{array}$ & 138 \\
\hline 9 & s. & & $\begin{array}{l}\text { Eaton's reagent, 110-148 } \\
{ }^{\circ} \mathrm{C}, 4-24 \mathrm{~h}\end{array}$ & 138,139 \\
\hline 10 & $\sqrt[N]{n}^{n}=$ & & $\mathrm{PPA}, 210^{\circ} \mathrm{C}, 24 \mathrm{~h}$ & 134,140 \\
\hline 11 & $\int_{3 / n}^{n=}=$ & & $\mathrm{PPA}, 210^{\circ} \mathrm{C}, 24 \mathrm{~h}$ & 134,140 \\
\hline
\end{tabular}




\begin{tabular}{|l|l|l|l|}
\hline 12 & PPA, $210^{\circ} \mathrm{C}, 24 \mathrm{~h}$ & 134,140 \\
\hline 14 & PPA, $210^{\circ} \mathrm{C}, 24 \mathrm{~h}$ & 134 \\
\hline 16 & PPA, $210^{\circ} \mathrm{C}, 24 \mathrm{~h}$ & 134,140 \\
\hline 17 & ${ }^{\circ} \mathrm{C}, 24 \mathrm{~h}$ & 134,140 \\
\hline
\end{tabular}

The possibility to prepare random copolymers and block-copolymers further extends the structural scope of PBI chemistries, as exemplified in Table 3. Mader and Benicewicz ${ }^{132,141}$ prepared a series of sulfonated random- or block PBI copolymers (Table 3; Entry 1). Random copolymers were obtained by substituting a fraction of the terephthalic acid with a sulfonated analogue. ${ }^{132}$ The corresponding segmented block copolymers were obtained by an initial preparation of oligomeric prepolymers of the different blocks, followed by combination at different ratios and further polymerization in PPA. ${ }^{141}$ The latter approach was also employed by Maity and Jana, ${ }^{142}$ Lee et al. ${ }^{143}$ and Schönberger et al. ${ }^{144}$ for the preparation of polybenzimidazole block copolymers of meta/para substituted phenylene linkages and poly(arylene ether sulfone) or poly(arylene ether) containing segments, respectively.

As discussed above, a large variety of dicarboxylic acids are available on a commercial basis or accessible via established synthetic procedures. This likely explains why the vast majority of the polybenzimidazole copolymers reported in the literature have been obtained by random copolymerization of DAB and two different dicarboxylic acids mixed at different ratios. Using this approach, structures containing sulfone (Table 3; Entry 2, 12, 15) 128, 131, 145 , hexafluoroisopropylidene (Table 3; Entry 3, 6) ${ }^{128,129,146}$ or arylene ether linkages (Table 3; Entry

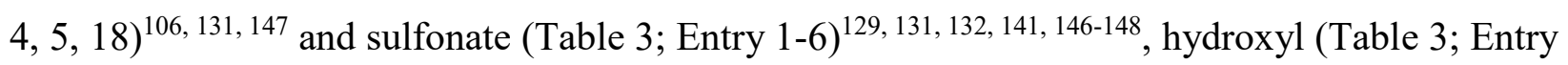


$8,13,14)^{100,149,150}$, amine (Table 3; Entry 7$)^{123}$ or bulky hydrocarbon functionalities (Table 3; Entry 10$)^{145}$ have been reported. The polycondensations are typically carried out in PPA at around $200^{\circ} \mathrm{C}$, but Eaton's reagent is used in some cases, ${ }^{129,} 147$ likely to circumvent solubility constraints.

The copolymer containing polyphenylquinoxaline blocks as reported by Henkensmeier et al. $^{151}$ and Seel and Benicewicz ${ }^{152}$ (Table 3; Entry 22) required an extension of the synthetic procedure, where the polyphenylquinoxaline units were formed at lower temperature $\left(123^{\circ} \mathrm{C}\right)$ and thereafter copolymerized with polybenzimidazole at typical polycondensation temperatures.

Table 3 PBI copolymers obtained by homogeneous solution polymerization of DAB and dicarboxylic acids. The temperatures listed in the table are the maximum temperatures reached during the polycondensation, and the given times represent the total duration of the process. The reader is referred to the original reference for full synthetic details.

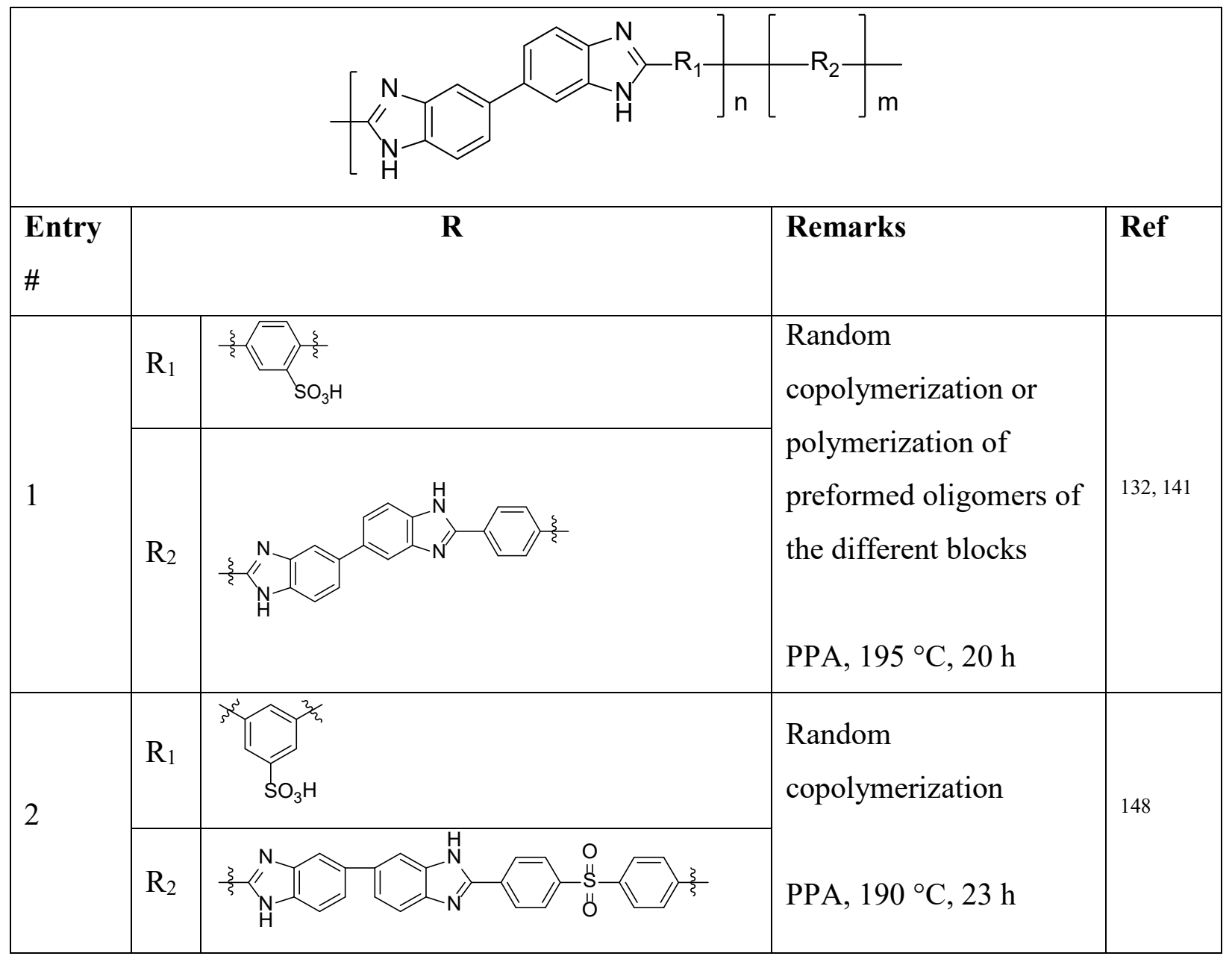




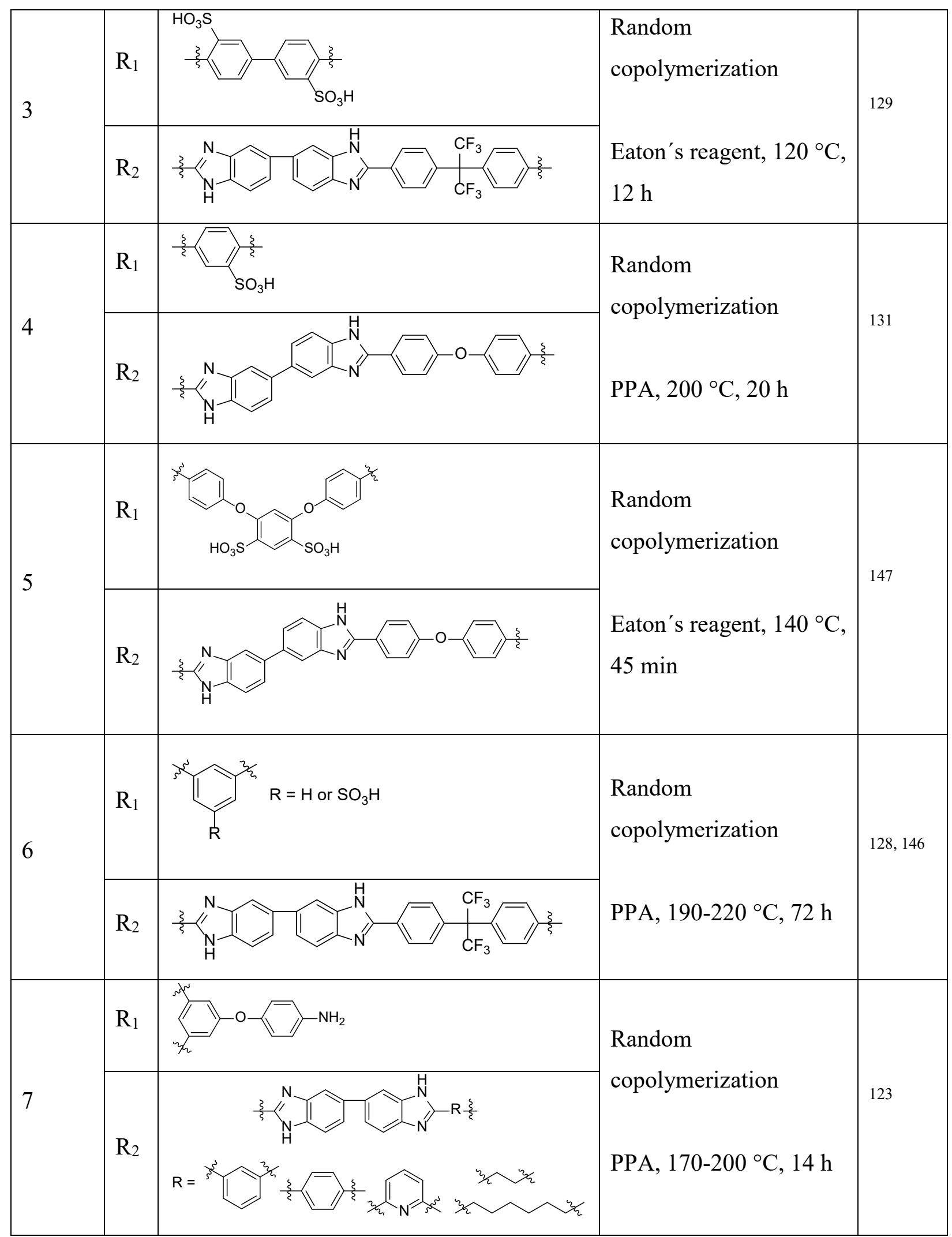




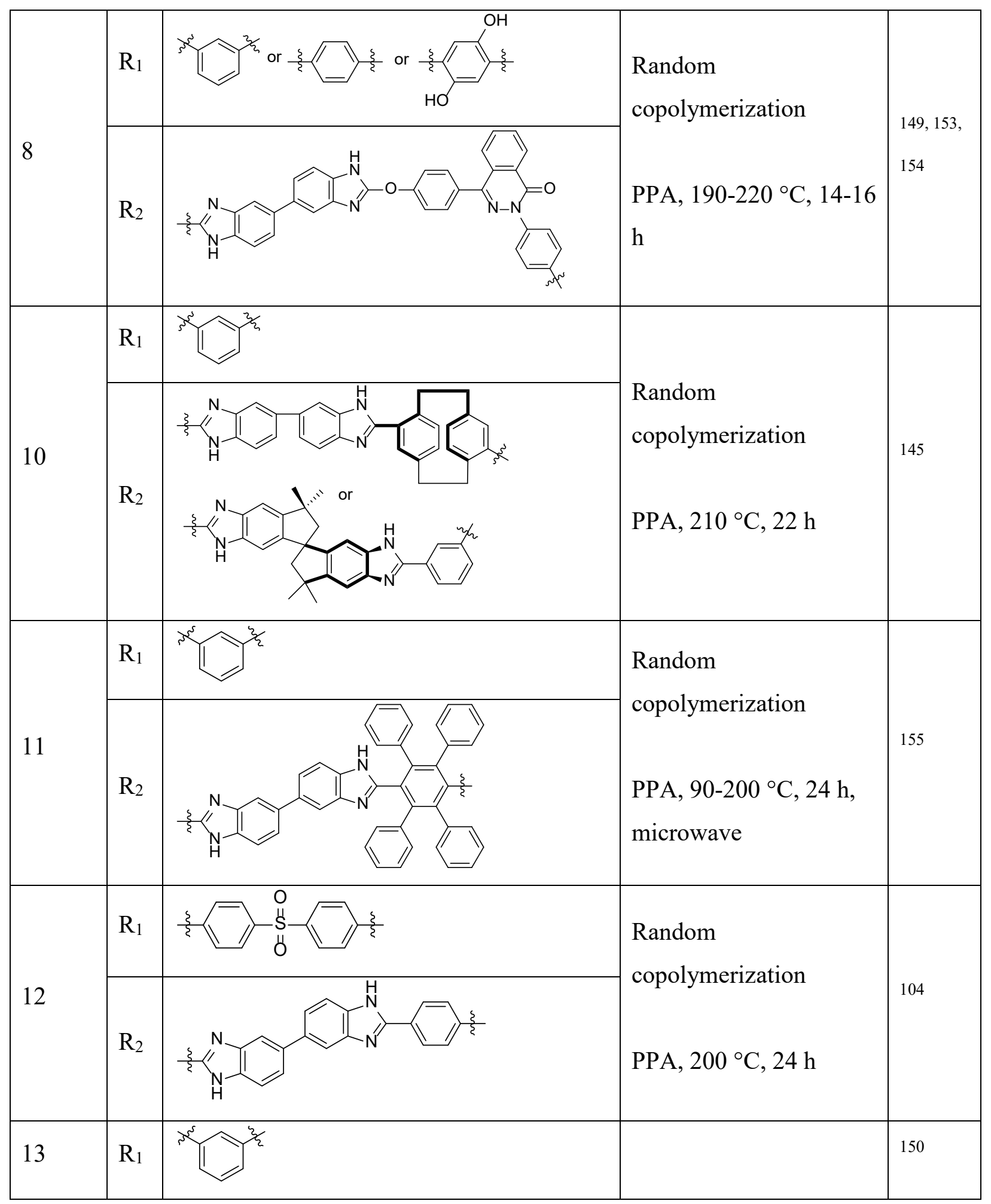




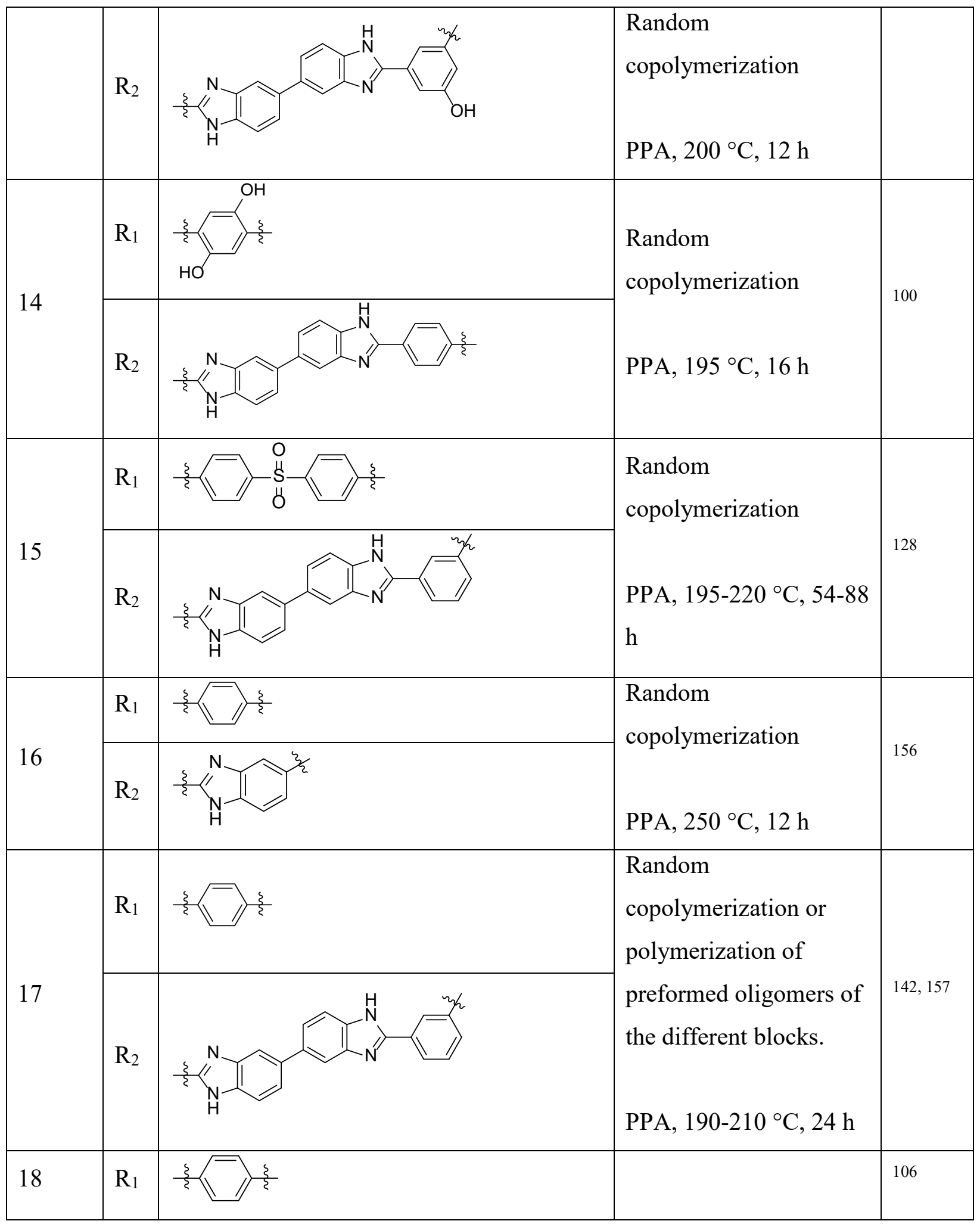




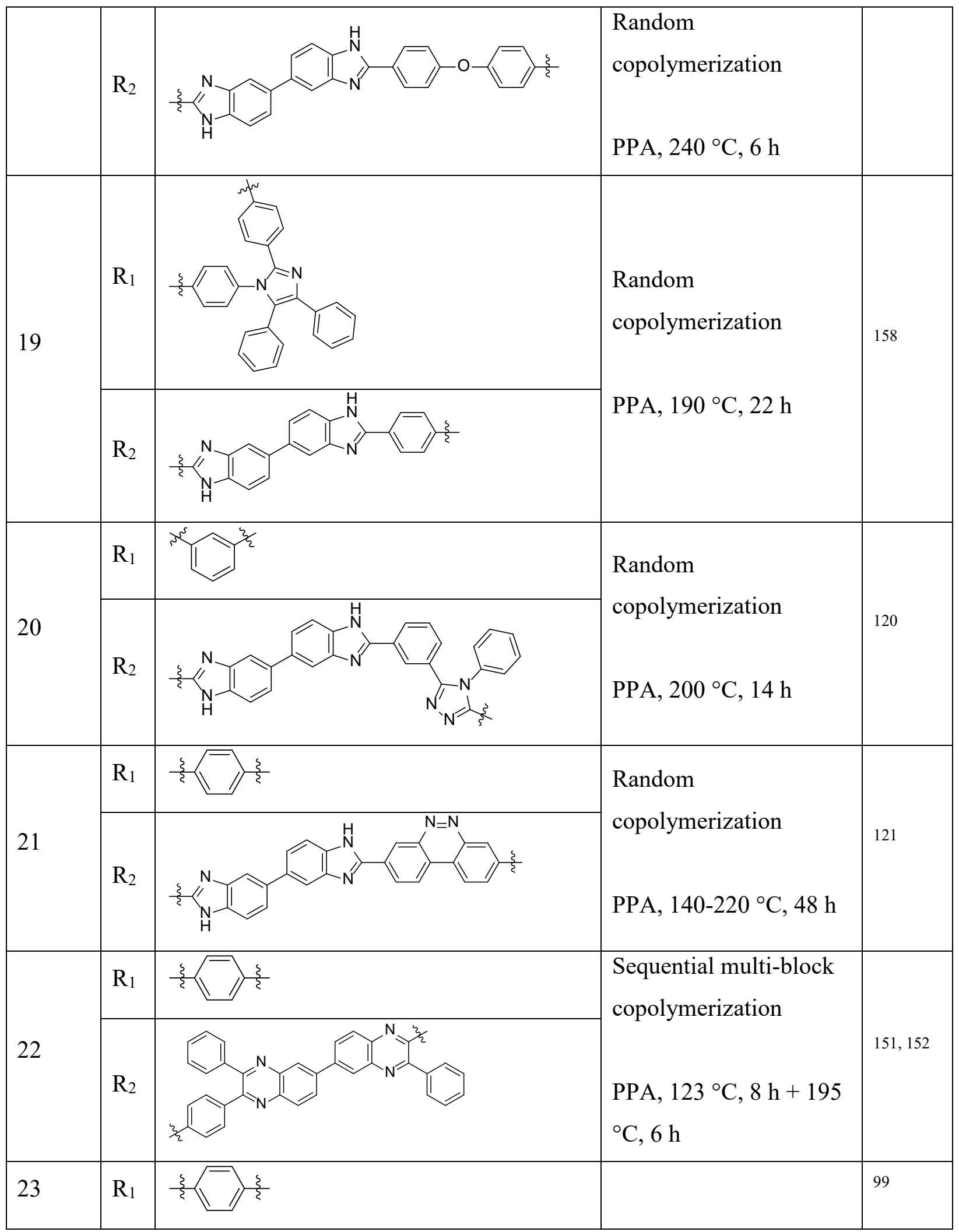




\begin{tabular}{|l|l|l|l|}
\hline Random & $\begin{array}{l}\text { apolymerization } \\
\text { copoly }\end{array}$ \\
PPA, $150-220^{\circ} \mathrm{C}, 23 \mathrm{~h}$
\end{tabular}

All PBI chemistries summarized in Table 3 were obtained by varying the dicarboxylic acid used during the copolymerization with DAB. However, there are also a few examples in the literature where PBI copolymers are obtained by varying the tetraamine. For example, an $N$-coupled and partly aliphatic PBI copolymer was obtained by copolymerizing isophthalic acid with a mixture DAB and an amino functional tetraamine, as shown in Scheme 2. ${ }^{159}$

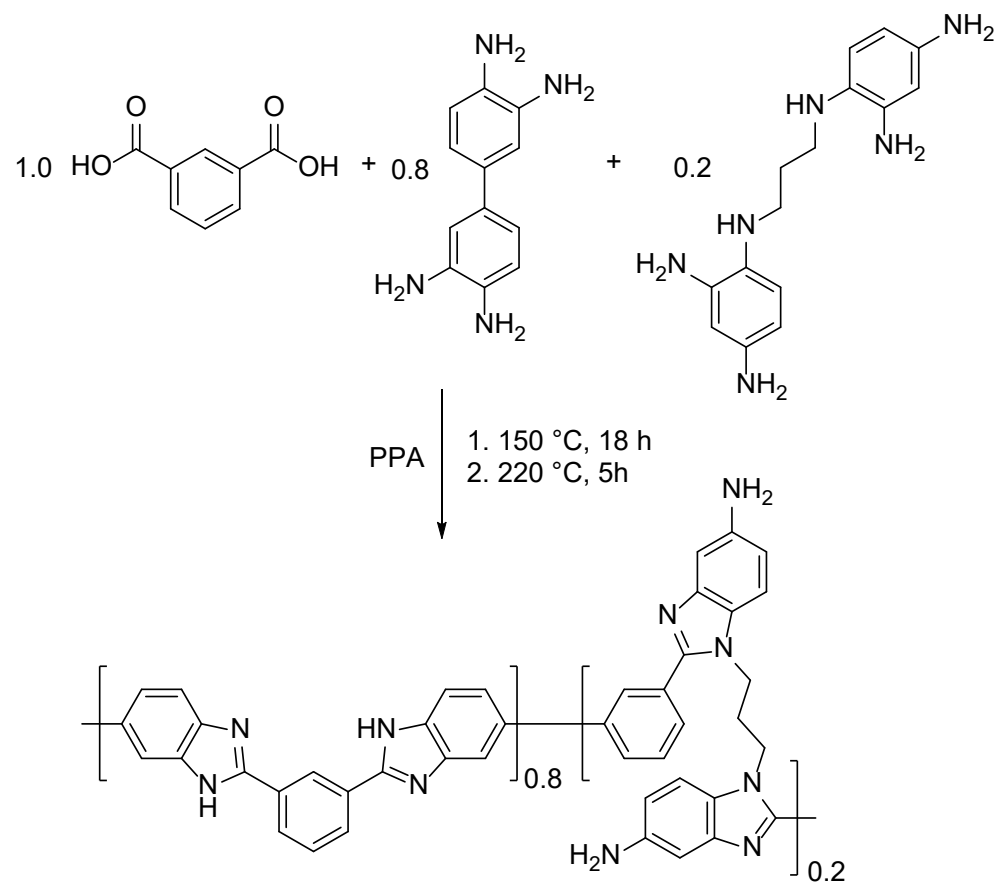

Scheme 2 Synthesis of amino-functional $N$-coupled PBI copolymer. ${ }^{159}$

A far less employed synthetic route is the base-catalyzed coupling of activated aromatic diflurides and bis[2-(4-hydroxyphenyl)benzimidazole]s. ${ }^{160,161}$ The process yields high molecular weight PBI in DMAc, but requires additional synthetic steps to obtain the dihydroxy terminated monomer that contains the benzimidazole structural units. However, the synthetic route may give access to polybenzimidazole chemistries that cannot be obtained from polycondensation using tetraamines 
and dicarboxylic acid derivatives. The methodology can also be used to produce organosoluble $N$ coupled polybenzimidazoles. ${ }^{162}$

The majority of the PBI chemistries presented in Table 1-3 have been developed in the high temperature polymer electrolyte membrane community, aiming at tailoring the interaction with doping acids or improving the mechanical robustness on the membrane level. For example, PBI structures with an increased content of heteroatom functionalities as hydrogen bond donors/acceptors often show an enhanced uptake of protic acids (see e.g. Table 1, Entry 19-25). An increased acid uptake typically lead to enhanced ion conductivity of the material but may compromise mechanical robustness, which will be further discussed in section 3. Substantial contributions to the extension of the structural scope of PBI has also been made in the gas separation community, where the efforts mainly have focused tailoring the selectivity and permeability by side chain modifications (see e.g. Table 1, Entry 5) or the development of structures with intrinsic porosity (see e.g. Table 3, Entry 10).

\subsection{Solubility, solution properties and molecular weight determination}

In addition to the strongly acidic solvent systems used for the homogenous solution polymerization reactions (PPA and/or Eaton's reagent), a small number of high-boiling polar aprotic solvents dissolve many of the polybenzimidazole derivatives reported in the literature. For $m$-PBI, $N, N$ dimethylacetamide (DMAc) is widely used and gives polymer solutions with suitable viscosity for dry spinning of fibers. ${ }^{3}$ Other options are $N, N$-dimethylformamide (DMF), N-methyl-2pyrrolidone (NMP) and dimethyl sulfoxide (DMSO). More unconventional solvent systems include ionic liquids such as 1-butyl-3-methylimidazolium chloride or hydroxide, which can give solutions with solid contents up to $10 \mathrm{wt} . \% .{ }^{163}$ Alternatively, ethanol containing a few weight percent of a hydroxide salt (e.g. $\mathrm{NaOH}$ or $\mathrm{KOH})$ readily dissolves $m$-PBI ${ }^{17,164}$ or AB-PBI. ${ }^{165}$

The degree of polymerization is typically estimated from Ubbelohde viscometry of polymer solutions using concentrated sulfuric acid as the solvent. For $m$-PBI the molecular weight can be calculated from intrinsic viscosity $[\eta]$, using empirical Mark-Houwink constants obtained from correlations to absolute weight average molecular weight $\left(M_{w}\right)$ determinations using light scattering measurements. The intrinsic viscosity should ideally be obtained from dual HugginsKramer extrapolation plots, but a less time-consuming single point method gives a good estimate of the intrinsic viscosity at $99 \%$ accuracy for low solid content solutions ${ }^{166}$ and is therefore widely 
used. $^{61,167}$ The intrinsic viscosity $[\eta]$ is calculated according to Equation 1 , where $\eta_{\text {sp }}$ denotes the specific viscosity and $C$ is the solid content.

$$
[\eta]=\left(\eta_{\mathrm{sp}}+\left(3 \times \ln \left(1+\eta_{\mathrm{sp}}\right)\right)\right) /(4 \times C)
$$

The first correlation between $M_{w}$ obtained from light scattering measurements and intrinsic viscosity data were reported by Kojima et al., ${ }^{168}$ for a polybenzimidazole derived from DAB and dimethyl 4,4'-oxybibenzoate (see Table 1; Entry 13). For $m$-PBI, two sets of Mark-Houwink constants determined at $25^{\circ} \mathrm{C}$ in sulfuric acid are available in the literature, as reported by Buckley et al. ${ }^{169}$ and Yuan et al. ${ }^{166}$ The former set was based on a measurement series with not more than three data points in the intrinsic viscosity range $0.30-1.02 \mathrm{dL} \mathrm{g}^{-1}$, measured at $25^{\circ} \mathrm{C}$ at solid content of $0.4 \mathrm{~g} \mathrm{dL}^{-1}$. The latter set was obtained in a broader intrinsic viscosity range of $0.32-1.26 \mathrm{dL} \mathrm{g}^{-1}$, and also included Mark-Houwink correlations in DMF with an addition of $4.5 \% \mathrm{LiCl}$. The intrinsic viscosity at $25^{\circ} \mathrm{C}$ was obtained from a measurements in the concentration range $0.1-1 \mathrm{~g} \mathrm{dL}^{-1}$. The relationship between $\log M_{w}$ and $\log [\eta]$ was found to diverge from linearity at $>1.07 \mathrm{dL} \mathrm{g}^{-1},{ }^{166}$ which suggests that invalid $m$-PBI $M_{w}$ estimates are obtained from the Mark-Houwink relationship at intrinsic viscosities corresponding to an $M_{w}$ higher than around $49500 \mathrm{~g} \mathrm{~mol}^{-1}$. Molecular weight determination by Maldi TOF/TOF mass spectrometry has recently been accomplished, which may enhance the precision of molecular weight determinations of PBI. ${ }^{170}$

Pure organic solvent-based solutions of $m$-PBI show limited stability since $m$-PBI tends to aggregate and eventually phase out from the solution due to intra- or intermolecular hydrogen bond interactions, which becomes even more problematic at high polymer concentrations. ${ }^{171,172}$ While some PBI grades can be easily dissolved at room temperature in DMAc, this may lead to gelation of the solution in some cases. Therefore, it is usually better to dissolve PBI at temperatures close to the boiling point of DMAc. The dissolution of some high molecular weight grades even requires pressurization in an autoclave to reach higher temperatures. A common way to prevent or, at least minimize these issues is, as also mentioned in the previous paragraph, to add a few percent of $\mathrm{LiCl}$ to the solution. The lithium cation has high charge density and effectively coordinates to the benzimidazole groups and breaks up the intra- or intermolecular hydrogen bond interactions, which not only stabilizes the solution but also greatly affects the viscosity. ${ }^{173-176}$ The work by Hanley et al. ${ }^{173}$ on the $m$-PBI/DMAc/ $\mathrm{LiCl}$ system suggests that the addition of $\mathrm{LiCl}$ results in 
changes in the chain conformation to a more extended state, which furthermore contributes to the increased viscosity of the solution.

The tendency of polybenzimidazoles to aggregate in organic solvents makes it difficult to determine the molecular weight using size exclusion chromatography (SEC). The SEC data available in the scientific literature have typically been obtained using DMAc as the mobile phase with an addition of $\mathrm{LiCl}$. Molecular weights calculated based on poly(methyl methacrylate) (PMMA) calibration curves seem to be overestimated due to aggregation, and the retention characteristics strongly depend on the $\mathrm{LiCl}$ concentration of the mobile phase. ${ }^{76}$ For example, for a $m$-PBI batch with an intrinsic viscosity $[\eta]$ of $1.31 \mathrm{dL} \mathrm{g}^{-1}$ (calculated from single-point measurement in $96 \% \mathrm{H}_{2} \mathrm{SO}_{4}$ at $30.0{ }^{\circ} \mathrm{C}$ at $0.5 \mathrm{~g} \mathrm{dL}^{-1}$ ) the $M_{w}$ calculated from the Mark-Houwink equation and SEC with PMMA calibration was 61.0 and $209.6 \mathrm{~kg} \mathrm{~mol}^{-1}$, respectively. ${ }^{167}$ Similarly, significant deviations between $M_{w}$ obtained from viscosity and SEC calibrated with polystyrene have been reported. ${ }^{177}$

It is apparent that there is a high degree of uncertainty in the absolute molecular weights obtained from viscosity as well as from SEC. The techniques are indeed suitable for e.g.

monitoring the degradation of PBIs behavior under different conditions, ${ }^{91,} 167$ but quantitative comparisons of molecular weight data from different sources are far from straightforward.

\subsection{N-substitution}

The nucleophilic nature of the benzimidazole groups has been widely utilized for $N$ functionalization of polybenzimidazoles via substitution reactions. A typical procedure is illustrated in Scheme 3 and involves deprotonation of the polybenzimidazole using a strong nonnucleophilic base (e.g. $\mathrm{LiH}$ or $\mathrm{NaH}$ ) in an organic solvent (e.g. DMSO), followed by addition of an alkyl halide. ${ }^{178}$ 


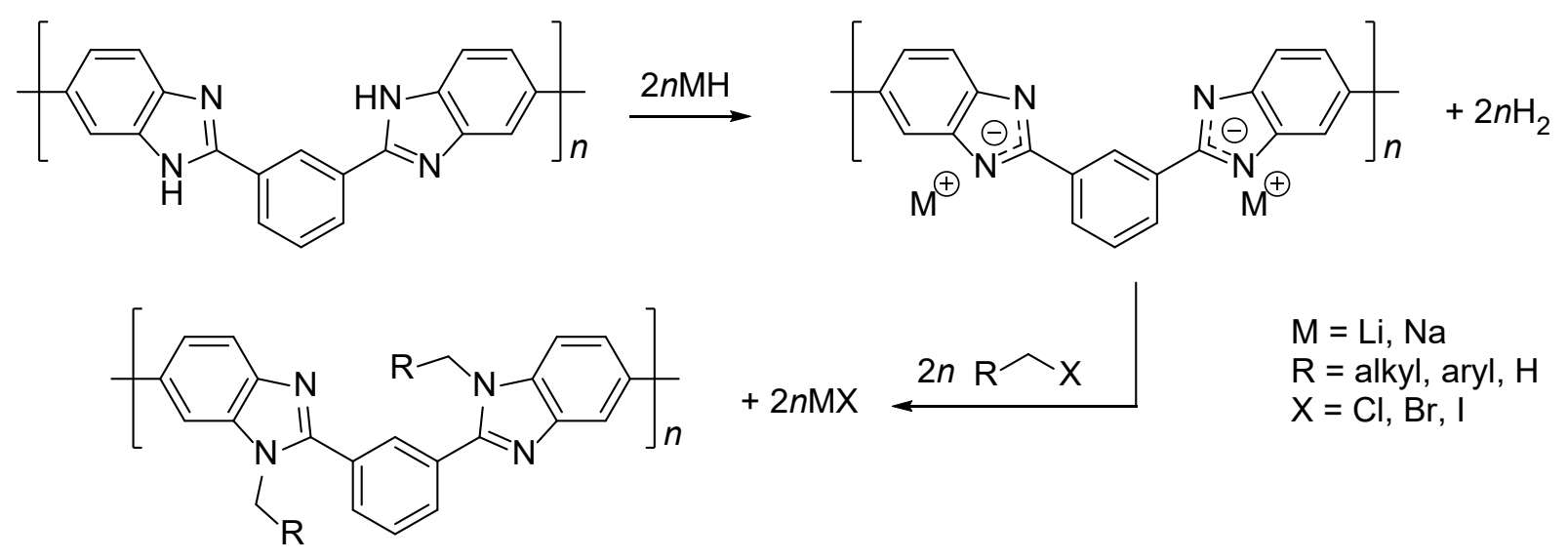

Scheme 3 General procedure for $N$-substitution of $m$-PBI.

The approach has been used for the preparation $N$-alkylated $m$-PBI as an effective method to improve organosolubility, ${ }^{179-182}$ to provide plasticity, and to enhance the free volume in the solid state ${ }^{86,183}$ Furthermore, the method renders a pathway to PBIs containing rotaxanes in the form of permethyl- $\beta$-cyclodextrin(s), ${ }^{179}$ crown ethers, ${ }^{184}$ furan, ${ }^{35}$ organosilanes, ${ }^{182}$ or ion exchange functionalities. ${ }^{185,186}$ The method can also be used for alkylsulfonation employing e.g. 1,3-propane sultone, ${ }^{187,188} 1$,4-butane sultone ${ }^{189,}, 190$ or sodium (4-bromomethyl)benzenesulfonate ${ }^{187,}, 191$ to give hydrophilic polyelectrolytes that become water soluble at high degrees of functionalization. Other protic acid containing functionalities can be grafted to polybenzimidazole in a similar fashion. For example, $N$-functionalization with diethyl 2-bromoethyl phosphonate was reported to occur under mild reaction conditions using potassium carbonate to activate the $m$-PBI. ${ }^{192} \mathrm{~A}$ stronger base $(\mathrm{NaH})$ was needed when 2-chloroethyl phosphonate was used due to the lower reactivity of alkyl chlorides in substitution reactions. On the other hand, 2-chloromethyl benzimidazole was successfully grafted to $m$-PBI by $N$-coupling without using base catalyst when the reaction was carried out in solid state during co-casting at relatively high temperatures $\left(120{ }^{\circ} \mathrm{C}\right) .{ }^{193}$ With reactive electrophiles, such as 1-bromo-2-(2-methoxyethoxy) ethane, the $N$-functionalization also proceeds smoothly under mildly alkaline conditions with $\mathrm{K}_{2} \mathrm{CO}_{3}$ as the catalyst. ${ }^{170}$

The reactivity of the benzimidazole groups in $N$-coupling reactions has also been explored in the context of new polybenzimidazole synthetic routes. As described by Hlil et al. ${ }^{194}$ and as illustrated in Scheme 4, bis(benzimidazolyl) and aromatic difluorides can be polymerized across the benzimidazole $N$-sites to give organosoluble $N$-coupled polybenzimidazoles in sulfolane in the 
presence of anhydrous potassium carbonate at $210{ }^{\circ} \mathrm{C}$. The structural scope was later extended to cover a large variety of $N$-coupled polybenzimidazole copolymers. ${ }^{195-199}$

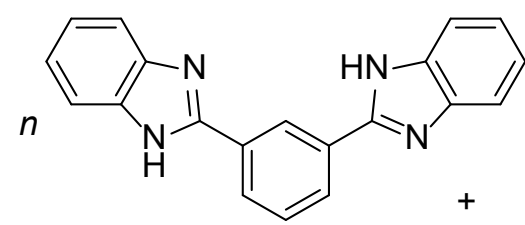

$n$

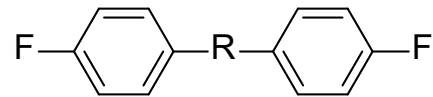

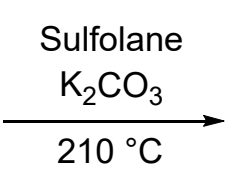<smiles>Nc1ccccc1</smiles>

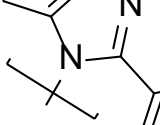

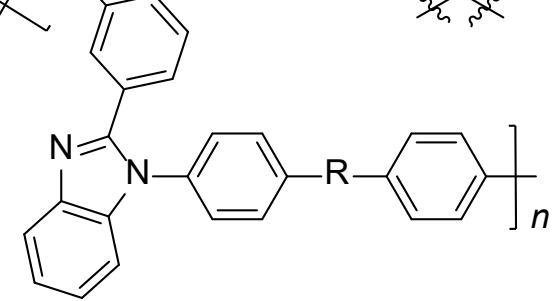

Scheme 4 Polybenzimidazole synthesis from bis(benzimidazole)benzene via $N$-coupling with activated aromatic diflurides.

\subsection{Crosslinked and branched structures}

As described in the previous section, polybenzimidazoles undergo $N$-substitution when reacted with an alkyl or aryl halide under basic conditions. The use of bifunctional alkyl or aryl halides as electrophiles crosslinks the polymer, which results in an insoluble material. Controlled crosslinking can be carried out by co-casting the polybenzimidazole from an organic solvent containing the bifunctional halomethyl electrophile and initiating the $\mathrm{N}$-substitution in the solid state at elevated temperatures. The method has been utilized to produce crosslinked $m$-PBI with a wide range of crosslinking agents such as $\alpha, \alpha^{\prime}$-dichloro- $p$-xylene (and derivatives thereof), ${ }^{36,}, 200$ $\alpha, \alpha^{\prime}$-dibromo- $p$-xylene, ${ }^{201} \quad$ 1,12-diiodododecane, ${ }^{202} \quad$ 1,3,5-tris(bromomethyl)benzene, ${ }^{203,} \quad 204$ dichloromethyl phosphinic acid, ${ }^{205}$ bismaleimide ${ }^{35}$ and silanes. ${ }^{206}$ Alternatively, $m$-PBI can be crosslinked in a heterogeneous process where the polymer film is immersed in a solution containing the crosslinking agent. For example, $m$-PBI treated in methanol containing divinylsulfone was found to effectively crosslink $m$-PBI by Michael addition. ${ }^{207}$ Similarly, crosslinking can be achieved by treating $m$-PBI with terephthaloyl chloride dissolved in tetrahydrofuran. ${ }^{32}$ The heterogeneous crosslinking chemistry depends on the diffusion of the crosslinker into the polymer matrix, and the crosslinking degree can therefore be uneven throughout the cross-section. ${ }^{207}$ 
Macromolecular crosslinking agents containing halomethyl groups react in a similar way, and yield covalently crosslinked interpenetrating networks. Halomethylated polysulfone, ${ }^{127,} 208$ poly(vinylbenzyl chloride), ${ }^{209,} 210$ or bromomethylated poly(aryl ether ketone) ${ }^{211}$ have been explored in this context. Such structures are prepared by co-casting the two polymers to form a polymer blend, and the crosslinking is thereafter initiated by heat treatment. The miscibility behavior of polybenzimidazole will be discussed in more detail in the following section.

The scope of polybenzimidazole crosslinking agents extends beyond the halomethylated compounds to bifunctional peroxides, which have been shown to react in a similar way in the solid state. ${ }^{212-216}$ Alternative crosslinking methods have also been developed based on Diels-Alder ${ }^{217}$ or Friedel-Crafts ${ }^{218}$ chemistry or coupling to various polybenzoxazine derivatives, ${ }^{219-222}$ as shown in Scheme 5. Heat treatment ${ }^{133,223,224}$ or electron beam irradiation ${ }^{225}$ can also result in crosslinking. The methodologies are operationally simple and of high technological relevance, ${ }^{5,224}$ but remain poorly understood from a mechanistic point of view.
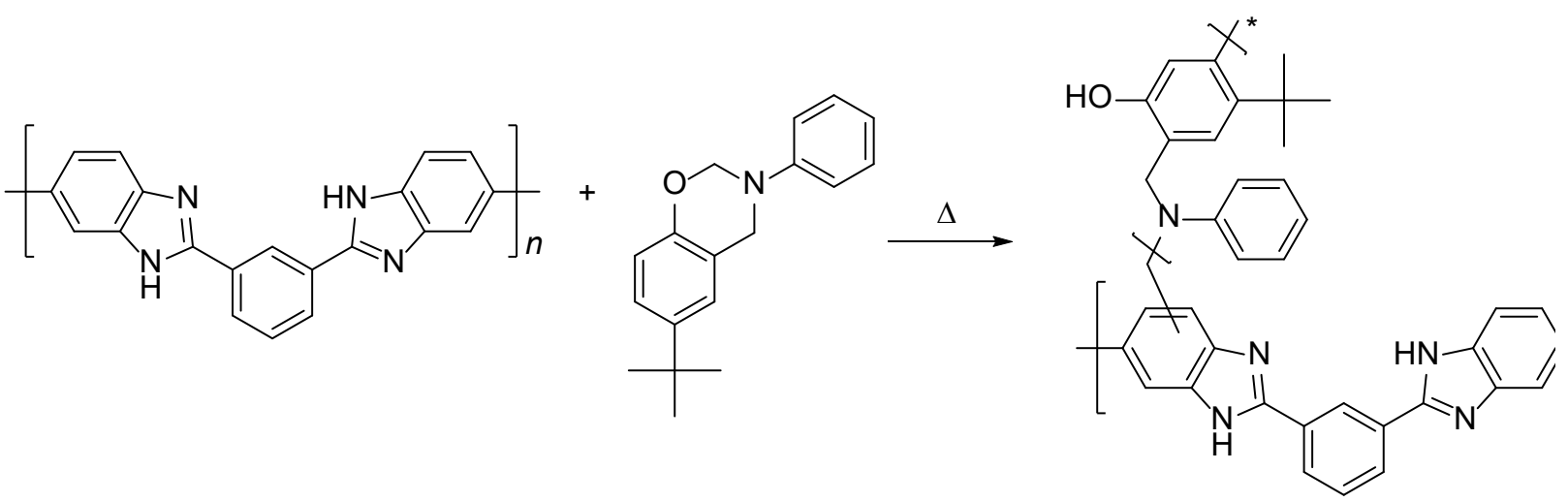

Scheme 5 Example of crosslinking of $m$-PBI by means of polybenzoxazine coupling. ${ }^{219}$

The vast majority of the crosslinking approaches reported in the literature are based on $\mathrm{N}$-coupling of the polymer chains. The procedure is straightforward and the degree of crosslinking can easily be adjusted by varying the mol ratio of the crosslinking agent relative to the polybenzimidazole repeat unit. From a chemical stability point of view, crosslinking via carbon-carbon linkages is likely preferred when the bond strength of the carbon-carbon bond relative to the carbon-nitrogen bond is considered. Furthermore, the crosslinking and functionalization based on $\mathrm{N}$-coupling consume $\mathrm{N}-\mathrm{H}$ functionalities, which is often undesired as it reduces the number of hydrogen bond 
donors in the polymer and could lead to decreased acid retention when used as fuel cell electrolyte. 226

\subsection{Polymer blends and interpenetrating polymer networks}

The development of binary blend systems based on aromatic PBIs was intensified after it was discovered that $m$-PBI and various poly(ether imide)s are fully miscible, which introduced a new approach to tailoring high performance materials. ${ }^{27-232}$ The compatibility between $m$-PBI and the poly(ether imide) polymers is connected to the intermolecular hydrogen bonding, which provides sufficient attractive forces to prevent phase separation during co-casting from organic solvents. ${ }^{233}$, ${ }^{234}$ However, some polyimide derivatives have been reported to be miscible with $m$-PBI in a limited composition range ${ }^{235}$ and phase separate when heated. ${ }^{236}$ Moon et al. ${ }^{237}$ recently reported that the addition of 1-methylimidazole as a compatibilizer effectively enhanced the phase dispersion.

The blending approach was initially explored in the context of high performance textile fibers development, but has later been utilized in electrochemical applications and resulted in an intensification in the research in this area. Over the years, the scope of binary systems that form miscible blends with $m$-PBI has been extended to poly(vinylpyrrolidone), ${ }^{238,239}$ poly(vinylidene fluoride), ${ }^{240}$ polyarylates (aromatic polyester derived from bisphenol A and terephthalic acid), ${ }^{174}$ polyamide-imide copolymers ${ }^{241}$ and polycarbonate. ${ }^{242}$ Binary systems of e.g. $m$-PBI and poly(vinyl alcohol) have also been explored, although the polymers phase separated during casting. $^{243}$

In the field of polymer electrolyte membranes, blends of PBIs and various protic ionomers have been widely explored. The research in this area was pioneered by Kerres et al., ${ }^{244,}{ }^{245}$ who successfully prepared blends of $m$-PBI and sulfonated polysulfone and sulfonated polyether ketone. The polymer blend films were prepared by co-casting and to avoid the instant precipitation of a polymeric salt due to the acid-base reaction between the two polymers, the acidic polymer was converted to a neutral salt form (e.g. $\mathrm{Li}^{+}$) before casting. After casting, the films were equilibrated in aqueous $\mathrm{HCl}$ to restore the sulfonic acid functionalities. The result is an ionically crosslinked polymer blend. Deeper studies on the $m$-PBI and sulfonated polysulfone blend system revealed, that the miscibility was governed by the specific interactions between the functional groups. ${ }^{246}$ Following this, the concept has been extended to a wide range of blend systems of $m$ PBI and various sulfonated derivatives of e.g. poly(arylene thioether)s, ${ }^{247}$ partially fluorinated 
poly(arylene(thio)ether) $\mathrm{s}^{202,248,249}$ and poly(arylene ether sulfone) copolymers. ${ }^{250}$ Blends of $m$ PBI and perfluorosulfonic acid $\left(\mathrm{Nafion}^{\circledR}\right)$ have been extensively studied using different cationic forms of the ionomer, and visually homogeneous blends could be obtained in the full composition range when the ammonium form was used. ${ }^{8}$ Furthermore, binary systems of poly(vinyl phosphonic acid) and $\mathrm{AB}-\mathrm{PBI}^{251}$ or other PBI chemistries have been prepared. ${ }^{252,253}$ However, in general, the miscibility behavior for the blends of PBI and acidic ionomers on the molecular scale remains to be explored in detail by e.g. analysis of the glass transition temperature and imaging.

\subsection{Solid state properties and stability}

In the solid state, the polymer chains of $m$-PBI are aligned with the aromatic rings in planar orientation as shown by molecular dynamics calculations, ${ }^{254}$ and neutron diffraction measurements support a lamellar structure. ${ }^{255}$ It is mostly amorphous, but the efficient chain packing results in a relatively high density of $1.33 \mathrm{~g} \mathrm{~cm}^{-3} .84,85$ For comparison, PBIs containing bulky alkane side chains, e.g. derived from 5-tert-butylisophthalic acid (Table 1; Entry 5) show a significantly lower density of $1.19 \mathrm{~g} \mathrm{~cm}^{-3}$ due to the disruption of the chain packing, which greatly affects the solubility and diffusivity of gases in the material. ${ }^{84,85}$

The benzimidazole units in PBI strongly interact with water by hydrogen bonding, which results in a high water affinity and conspicuous sorption of water. ${ }^{256}$ From a fully humidified atmosphere or after treatment in liquid water at room temperature, the water uptake of $m$-PBI has been reported to range from $2.5-3.2 \mathrm{H}_{2} \mathrm{O}$ per polymer repeat unit ${ }^{257-259}$ or $15-20 \%$ on a weight basis. Even after drying at temperatures up to $180^{\circ} \mathrm{C}$ under vacuum for $24 \mathrm{~h}$, characteristic signals originating from water can be seen in the FTIR and NMR spectra, which indicate that water is strongly associated with the polymer. ${ }^{257-259}$ It implies that even a PBI that is referred to as completely dry, may contain a relatively large amount of water.

A direct consequence of the water sorption is significant plasticization due to the interference with the intermolecular hydrogen bonding between the polymer chains. In the dry form, the elastic modulus of pure $m$-PBI is around 3-4 GPa at room temperature, while the engineering tensile strength at break at around 5-10\% elongation is 100-160 MPa depending on the molecular weight of the polymer. ${ }^{127,260}$ Under fully humidified conditions, the elongation at break can be considerably higher $(75 \%) .,{ }^{9}, 167$ 
The glass transition temperature $T_{g}$ of $m$-PBI is in the range of $400-450{ }^{\circ} \mathrm{C}$, depending on the measurement technique and the experimental conditions. ${ }^{85,123,157,231}$ The $T_{g}$ of $p$-PBI is around $60{ }^{\circ} \mathrm{C}$ lower as compared with $m$-PBI,${ }^{157}$ while PBI derivatives with e.g. flexible side chains ${ }^{123,183}$ or $m / p$-PBI block copolymers ${ }^{142}$ show even lower $T_{g}$ of $200-300{ }^{\circ} \mathrm{C}$.

Under inert atmosphere, $m$-PBI is thermally stable at temperatures up to $500{ }^{\circ} \mathrm{C}$, but significant changes in the FTIR spectrum can be seen after exposure to temperatures above 400 ${ }^{\circ} \mathrm{C}$ on a longer time scale of $16 \mathrm{~h} .{ }^{224}$ Under air atmosphere, the maximum operating temperature of $m$-PBI is significantly lower and severe degradation can be seen after exposure at temperatures above $300{ }^{\circ} \mathrm{C}$ for $16 \mathrm{~h}^{224}$ When treated isothermally at $390{ }^{\circ} \mathrm{C}$ for $33 \mathrm{~h}$, a $50 \%$ weight loss has been recorded as a result of oxidative degradation. ${ }^{261}$ The model system studies by Gaudiana and Conley ${ }^{262}$ show that the initial attack occurs at the benzenoid C2 position, i.e. the carbon atom linking the benzenoid ring and the phenylene groups. This is also the case when $m$-PBI is treated under radical-oxidative conditions in Fenton solution, where the initial radical attack at the C2 position leads to ring opening and ultimately polymer chain scission. ${ }^{177}$ Introduction of pyridine units as radical scavengers (e.g. Table 1; Entry 27) could potentially improve the radical oxidative stability. ${ }^{115}$

\section{Protic polybenzimidazoliums}

\subsection{Interaction with protic acids and acid sorption}

Per definition, all PBIs contain benzimidazole groups as part of the main chain. Since the benzimidazole groups contain Brønsted base functionalities, PBIs react and interact with protic acids. The result is the formation of a protic polybenzimidazolium ionene, as exemplified for $m$ PBI in Scheme 6. The position of the equilibrium depends on the strength and concentration of the protic acid, but the moderate $\mathrm{p} K_{\mathrm{aH}}$ value of 5.6 for the benzimidazole- $\mathrm{H}^{+}$ion suggests that quantitative protonation of PBI should occur even with relatively weak protic acids.

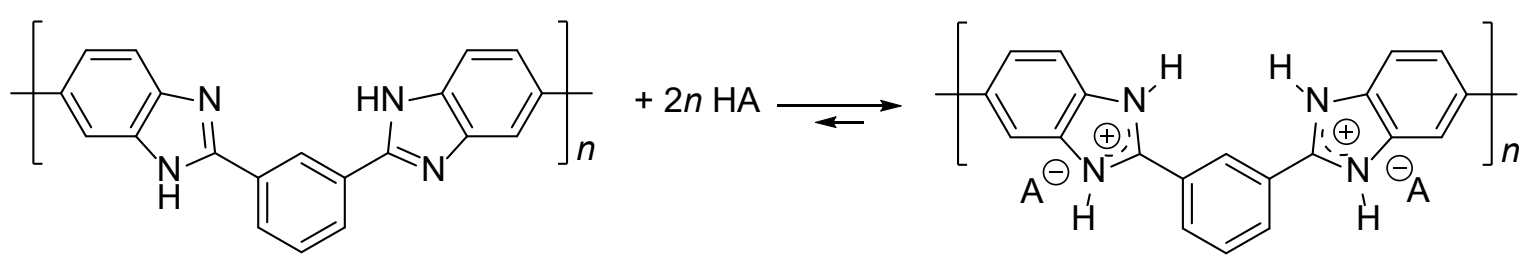


Scheme 6 The acid-base reaction between $m$-PBI and two equivalents of a monoprotic acid HA to form a protic polybenzimidazolium ionene.

As described in section 2.1, the polycondensation reaction of PBI is carried out in strongly acidic solvents (PPA or Eaton's reagent), which implies that the growing polymer chains are, in fact, in the fully ionic form as a protic polybenzimidazolium during synthesis. In the work-up procedure, the polymer is treated with large excess of basic aqueous solution (e.g. carbonate) to wash out the residual acid and to obtain the charge-neutral polybenzimidazole. In this process, the PPA is also hydrolyzed to orthophosphoric acid $\left(\mathrm{H}_{3} \mathrm{PO}_{4}\right)$ and due to the strong interactions between the polymer and $\mathrm{H}_{3} \mathrm{PO}_{4}$, extensive washing is required to completely wash out the $\mathrm{H}_{3} \mathrm{PO}_{4}$ residuals.

The acid-base chemistry between $m$-PBI and various inorganic and organic acids has been studied extensively in the literature during the last 20 years, including $\mathrm{H}_{2} \mathrm{SO}_{4},{ }^{263-268} \mathrm{HClO}_{4},{ }^{263}$ $\mathrm{HBr},{ }^{264} \mathrm{HCl}_{2}{ }^{266} \mathrm{HNO}_{3},{ }^{263} \mathrm{CH}_{3} \mathrm{SO}_{3} \mathrm{H}$ and $\mathrm{CH}_{3} \mathrm{CH}_{2} \mathrm{SO}_{3} \mathrm{H} .{ }^{266}$ However, the $\mathrm{PBI} / \mathrm{H}_{3} \mathrm{PO}_{4}$ system has been most thoroughly studied in the literature after it was reported as a promising proton conducting polymer electrolyte working at temperatures up to $200{ }^{\circ} \mathrm{C} .{ }^{37}$

When soaked in aqueous $\mathrm{H}_{3} \mathrm{PO}_{4}, m$-PBI shows a significant $\mathrm{H}_{3} \mathrm{PO}_{4}$ uptake, which depends on the $\mathrm{H}_{3} \mathrm{PO}_{4}$ concentration of the bulk solution as summarized in Figure 2 based on sorption data in the literature. ${ }^{62,84,258,265,269,270} \mathrm{The}_{3} \mathrm{PO}_{4}$ uptake is given as the acid doping level (ADL), i.e. normalized as the number of $\mathrm{H}_{3} \mathrm{PO}_{4}$ per polymer repeat unit. Hence, an ADL of 2 corresponds to the stoichiometric salt formation as shown in Scheme 5. As shown in Figure 2, this is achieved when $m$-PBI is equilibrated in $2 \mathrm{~mol} \mathrm{~L}^{-1} \mathrm{H}_{3} \mathrm{PO}_{4}$ at room temperature. The ADL increases gradually with increasing $\mathrm{H}_{3} \mathrm{PO}_{4}$ concentration until an $\mathrm{ADL}$ of around 5 is obtained in $12.5 \mathrm{~mol} \mathrm{~L}^{-1} \mathrm{H}_{3} \mathrm{PO}_{4}$. Further increasing the $\mathrm{H}_{3} \mathrm{PO}_{4}$ concentration results in a rapidly increasing ADL. In $14.8 \mathrm{~mol} \mathrm{~L}^{-1}$ (corresponding to $85 \mathrm{wt} . \% \mathrm{H}_{3} \mathrm{PO}_{4}$ ), the $\mathrm{ADL}$ reaches around 11 and the excessive $\mathrm{H}_{3} \mathrm{PO}_{4}$ uptake results in a dimensional swelling of $150-250 \% .{ }^{103,271}$ At room temperature the equilibrium ADL is reached after a few days. ${ }^{258}$ Elevated temperatures result in a faster $\mathrm{H}_{3} \mathrm{PO}_{4}$ uptake and higher equilibrium ADL, and eventually lead to complete dissolution. ${ }^{272}$ For example, $m$-PBI (Table 1; Entry 1) and the commercially available ether-linked PBI-OO (Table 2; Entry 6) dissolve completely in excess phosphoric acid at $150{ }^{\circ} \mathrm{C} .{ }^{272,273}$ 


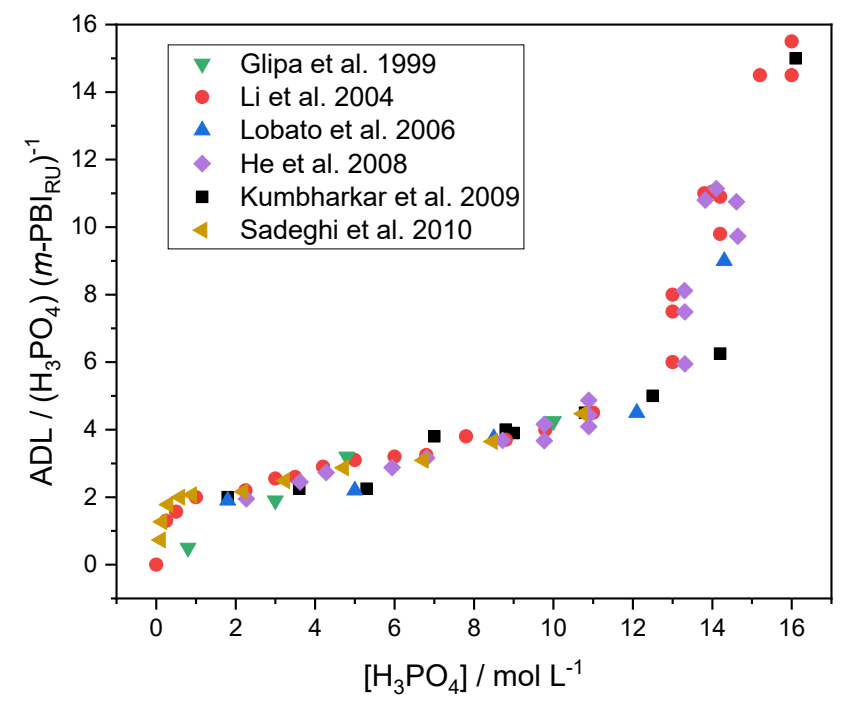

Figure $2 \mathrm{H}_{3} \mathrm{PO}_{4}$ sorption isotherm $\left(20-25{ }^{\circ} \mathrm{C}\right)$ for $m$-PBI normalized as the number of $\mathrm{H}_{3} \mathrm{PO}_{4}$ per polymer repeat unit as a function of $\mathrm{H}_{3} \mathrm{PO}_{4}$ concentration at equilibrium. The data points are taken from the work by Glipa et al., ${ }^{265}$ Li et al., ${ }^{258}$ Lobato et al., ${ }^{62}$ He et al., ${ }^{269}$ Kumbharkar et al. ${ }^{84}$ and Sadeghi et al. ${ }^{270}$

The acid-base chemistry between $m$-PBI and $\mathrm{H}_{2} \mathrm{SO}_{4},{ }^{264,}{ }^{266} \mathrm{H}_{3} \mathrm{PO}_{4},{ }^{258,}$, 264, ${ }^{266} \mathrm{HCl}^{266} \mathrm{HBr}^{264}$ $\mathrm{CH}_{3} \mathrm{SO}_{3} \mathrm{H}^{266}$ and $\mathrm{CH}_{3} \mathrm{CH}_{2} \mathrm{SO}_{3} \mathrm{H}^{266}$ has been thoroughly studied by means of Fourier transform infra-red spectroscopy (FT-IR). Here, the development of a broad N-H stretching absorption band in the region $2500-3600 \mathrm{~cm}^{-1}$ has been assigned to the formation of a protic polybenzimidazolium. Based on FT-IR studies, Kawahara et al. ${ }^{266}$ reported that the protic polybenzimidazolium was not formed quantitatively in the $m-\mathrm{PBI} / \mathrm{H}_{3} \mathrm{PO}_{4}$ system, although the FT-IR and Raman studies by Li et al. ${ }^{258}$ and the FT-IR studies by Bouchet and Siebert ${ }^{264}$ supported the opposite. The equilibrium constant for the protonation of $m$-PBI in $\mathrm{H}_{3} \mathrm{PO}_{4}$ at $25{ }^{\circ} \mathrm{C}$ was estimated by $\mathrm{Ma}$ et al. ${ }^{274}$ to $1.17 \times$ $10^{3}$ based on the $\mathrm{p} K_{\mathrm{a}}$ values of relevant model compounds. More recent Raman studies on the AB$\mathrm{PBI} / \mathrm{H}_{3} \mathrm{PO}_{4}$ system support quantitative protic polybenzimidazolium formation in $\mathrm{H}_{3} \mathrm{PO}_{4}$ when a large excess of $\mathrm{H}_{3} \mathrm{PO}_{4}$ is present. ${ }^{275,276}$ Nuclear magnetic resonance (NMR) spectroscopy further proves the formation of protic polybenzimidazolium with phosphate counter anions in the $m$ $\mathrm{PBI} / \mathrm{H}_{3} \mathrm{PO}_{4}$ system. ${ }^{277} \mathrm{NMR}$ data also reveal that the exchange of protons between the protic 
polybenzimidazolium and the excess phosphoric acid is around nine orders of magnitude slower than that between the phosphate species, indicating that the interaction is fully ionic. ${ }^{278}$

The first step towards a theoretical approach to describe the $\mathrm{H}_{3} \mathrm{PO}_{4}$ sorption in $m$-PBI was reported by He et al., ${ }^{279}$ using the Scatchard method. It was suggested that two chemically different sites providing different coordination strengths were present at low ADLs with dissociation constants of $5.4 \times 10^{-4}$ and $3.6 \times 10^{-4}$, which is about 5-10 times lower than for aqueous phosphoric acid. At higher ADLs, the two interaction mechanisms of the acid with the basic polymer initiate a multi-layer sorption process, which can be described by the Brunauer-Emmett-Teller (BET) isotherm, ${ }^{269}$ the dual-mode sorption or the combined sorption of Langmuir-type and Henry's law. ${ }^{270}$ Korte et al. ${ }^{280}$ recently introduced a modified BET model based on the acid doping data on both $m$-PBI and cross-linked AB-PBI (Fumapem AM-55) membranes in association with Raman spectra.

It is worth noting that the $\mathrm{H}_{3} \mathrm{PO}_{4} / \mathrm{PBI}$ systems are chemically complex systems containing various phosphoric oxoacid species as well as water. ${ }^{281}$ For the protic polybenzimidazolium system of $m$-PBI- $\mathrm{H}_{3} \mathrm{PO}_{4}$ with acid contents below the stoichiometric composition, the water uptake is reduced as compared with the pure $m$-PBI. ${ }^{258}$ At higher acid contents, on the other hand, the water uptake increases significantly due the hygroscopic nature of the excess acid.

\subsection{Thermal, chemical and dimensional stability}

Thermogravimetric analysis at linear heating rates of $10-15^{\circ} \mathrm{C} \min ^{-1}$ of pure $m$-PBI in air show a major onset of oxidative pyrolysis at around 500-550 ${ }^{\circ} \mathrm{C} .{ }^{167}$, 207 The protic $m-\mathrm{PBI}-\mathrm{H}_{3} \mathrm{PO}_{4}$ polybenzimidazolium complex near the stoichiometric composition was found to be even more thermally stable than the pristine $m$-PBI, ${ }^{3}$ but showed a continuous weight loss due to the loss of water and formation of phosphoric acid anhydrides. ${ }^{137}$ The complex with e.g. $\mathrm{H}_{2} \mathrm{SO}_{4}$, on the other hand, showed a major onset of weight loss at around $200{ }^{\circ} \mathrm{C} .{ }^{266}$ Severe degradation of protic $m$ PBI- $\mathrm{H}_{3} \mathrm{PO}_{4}$ polybenzimidazoliums has been observed under steam electrolysis conditions. ${ }^{8}$ It was postulated that the degradation was due to hydrolysis of the membrane, but whether the degradation is a purely chemical process or accelerated by the electrical potential gradient and ion current across the membrane under electrolysis conditions remains to be clarified.

As described in section 2.6, the chemical stability of PBI is often assessed in the literature under Fenton conditions, even though the technological relevance of this test in connection to e.g. 
fuel cell durability remains under debate. In this connection, some studies indicate that the presence of $\mathrm{H}_{3} \mathrm{PO}_{4}$ significantly improves the radical-oxidative stability of $m$-PBI. One of the reasons is that $\mathrm{H}_{3} \mathrm{PO}_{4}$ reduces the decomposition of $\mathrm{H}_{2} \mathrm{O}_{2}$ to hydroxyl or hydroperoxyl radicals by complexing with the $\mathrm{Fe}(\mathrm{II})$ catalyst as iron phosphate and by lowering the $\mathrm{pH} .{ }^{282}$ Furthermore, the protic polybenzimidazolium is highly electron deficient and hydroxyl radicals tend to react faster with electron-rich aromatic systems. ${ }^{283}$ On the other hand, $\mathrm{Xu}$ et al. ${ }^{122}$ noticed that a $\mathrm{H}_{3} \mathrm{PO}_{4}$ doped amino-functional PBI derivative (Table 1, Entry 34), showed enhanced embrittlement during the Fenton tests as compared with the pristine polymer. It was rationalized that this could be a result of increased porosity, and thus not necessarily an effect of enhanced polymer degradation. Furthermore, crosslinking has repeatedly been shown to reduce the rate of weight loss during the Fenton test or extend the time until severe embrittlement or spontaneous disintegration is observed. ${ }^{122,201,224,284}$

Another consequence of the excessive uptake of $\mathrm{H}_{3} \mathrm{PO}_{4}$ in $m$-PBI is the release of the intermolecular hydrogen bonding and swelling, which drastically alter the mechanical characteristics. At excess $\mathrm{H}_{3} \mathrm{PO}_{4}$, significant plasticization occur as shown by reduced tensile strength at break and elastic modulus along with increased elongation at break. For $m$-PBI of intermediate molecular weight, the elastic modulus decreases from $4 \mathrm{GPa}$ for the pristine $m$-PBI at room temperature to 176 and $38 \mathrm{MPa}$ at 6 and $12 \mathrm{H}_{3} \mathrm{PO}_{4}$ per polymer repeat unit, respectively. ${ }^{127}$ By further increasing the temperature to $130^{\circ} \mathrm{C}$, the elastic modulus drops to a few $\mathrm{MPa} .{ }^{8,271} \mathrm{On}$ the other hand, at low $\mathrm{H}_{3} \mathrm{PO}_{4}$ contents near the stoichiometric composition (Scheme 5), the elastic modulus is increased compared with the pristine $m$-PBI, likely due to the electrostatic interactions in the fully ionized system. ${ }^{164}$ It has recently been shown that stoichiometric $\mathrm{H}_{3} \mathrm{PO}_{4}$ or $\mathrm{H}_{2} \mathrm{SO}_{4}$ complexes with $m$-PBI possess a reduced fractional free volume and reduced $d$-spacing due to the electrostatic interactions, which has a great impact on the permeability and selectivity of gases. ${ }^{34}$

The research and development of crosslinked PBI chemistries, as described in section 2.4, have mainly addressed the mitigation of plasticization at high $\mathrm{H}_{3} \mathrm{PO}_{4}$ loadings. The crosslinking reduces the $\mathrm{H}_{3} \mathrm{PO}_{4}$ uptake, which is due to a combination of the restricted dimensional swelling, and the sacrifice of Brønsted base sites in the polymer chain from crosslinking chemistry based on $N$-coupling. From this perspective, crosslinking chemistries that are not based on $N$-coupling 5,133 , 224 or development of PBI backbone chemistries with intrinsically improved creep resistance ${ }^{4,101,}$ 102, 285 appear as the most attractive routes to pursue. 


\subsection{Ion conductivity and transport characteristics}

While pure $m$-PBI is an electrical insulator, the excess uptake of protic acids such as $\mathrm{H}_{3} \mathrm{PO}_{4}$, $\mathrm{H}_{2} \mathrm{SO}_{4}, \mathrm{HClO}_{4}, \mathrm{HNO}_{3}$ or $\mathrm{HCl}$ results in an ion conducting material. ${ }^{263}$ The conductivity varies depending on the intrinsic conductivity characteristics of the acid as well as on the acid and water content within the materials, which can be adjusted by equilibrating the polymer in acid of different concentrations. At a certain acid loading, the $m-\mathrm{PBI}-\mathrm{H}_{2} \mathrm{SO}_{4}$ system shows the highest conductivity of the screened protic acids. ${ }^{263,264}$ The high ion conductivity in $\mathrm{H}_{2} \mathrm{SO}_{4}$ in combination with the low crossover of e.g. cationic vanadium species has triggered substantial interest in this electrolyte system for redox flow battery applications recently. ${ }^{12-14,17-19}$

For many years, $m$-PBI- $\mathrm{H}_{3} \mathrm{PO}_{4}$ has been considered the most technologically relevant electrolyte system, due to the lower vapor pressure and high thermal stability of $\mathrm{H}_{3} \mathrm{PO}_{4}$, which allows for high ion conductivity at low water activity and at temperatures up to $200{ }^{\circ} \mathrm{C} .{ }^{37}$ The conductivity is mediated by the excess acid within the structure and thus increases with increasing ADL. Conductivity data from the literature for $m$-PBI at different ADL, recorded at $160{ }^{\circ} \mathrm{C}$ and under dry conditions, are summarized in Figure 3. At the ADL of 2, which corresponds to the stoichiometric composition, as shown in Scheme 5, the ion conductivity is $10^{-6} \mathrm{~S} \mathrm{~cm}^{-1}$. At a slightly lower $\mathrm{H}_{3} \mathrm{PO}_{4} \mathrm{ADL}$ of 1.7 , the conductivity is around 3 orders of magnitude lower. However, at a slight excess of $\mathrm{H}_{3} \mathrm{PO}_{4}$ corresponding to an ADL of 5-6 the conductivity increases dramatically and reaches a range of $10^{-2}-10^{-1} \mathrm{~S} \mathrm{~cm}^{-1}$. By further increasing the ADL to 32, the conductivity at $160{ }^{\circ} \mathrm{C}$ can reach as high as $0.2-0.3 \mathrm{~S} \mathrm{~cm}^{-1}$, which can be compared with around $0.6 \mathrm{~S} \mathrm{~cm}^{-1}$ for $85 \%$ aqueous $\mathrm{H}_{3} \mathrm{PO}_{4}$. The data presented in Figure 3 were recorded for dense films of $m$-PBI with a typical thickness of 50-100 $\mu \mathrm{m}$, and the $\mathrm{H}_{3} \mathrm{PO}_{4}$ uptake characteristics can be further tailored by introducing (meso)porosity by adding porogens during film formation, such as phthalates (dissolved in methanol) ${ }^{286}$ or silica nanoparticles (dissolved in $\mathrm{NH}_{4} \mathrm{HF}_{2}$ ). ${ }^{287}$ 


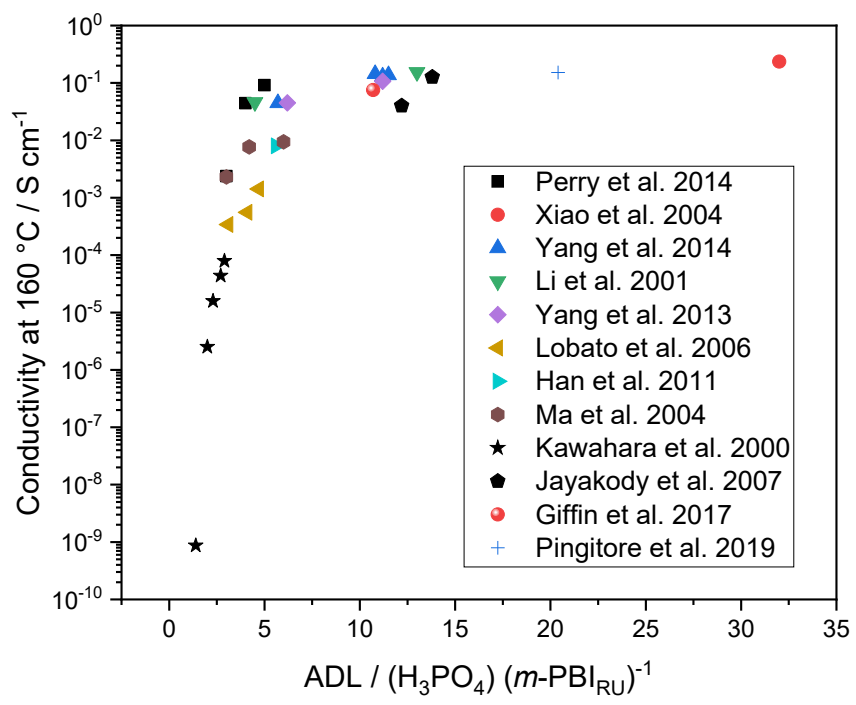

Figure 3 Ion conductivity of $m$-PBI at $160^{\circ} \mathrm{C}$ as function of ADL compiled based on the data reported by Perry et al., ${ }^{288}$ Xiao et al., ${ }^{83}$ Yang et al., ${ }^{61}$ Li et al., ${ }^{289}$ Lobato et al., ${ }^{62}$ Han et al., ${ }^{212}$ Ma et al., ${ }^{274}$ Kawahara et al., ${ }^{266}$ Jayakody et al., ${ }^{290}$ Giffin et al., ${ }^{291}$ and Pingitore et al. ${ }^{4}$

The subtraction of protons from phosphoric acid by the formation of the protic polybenzimidazolium and the resulting electrostatic interactions with the phosphate anions reduces the proton mobility and proton acceptor availability, which results in a significant reduction of the conductivity as compared with pure phosphoric acid. ${ }^{292}$ However, addition of water to the system by e.g. active humidification or by absorption of product water in fuel cells, results in a significant conductivity increase due the formation of mobile charge carriers, such as $\mathrm{H}_{3} \mathrm{O}^{+}{ }^{278}$ It also suppresses the condensation of $\mathrm{H}_{3} \mathrm{PO}_{4}$ to oligomeric and polymeric phosphoric oxoacid species with lower conductivity. ${ }^{274}$ For example, for $m$-PBI with an acid content corresponding to 11 $\mathrm{H}_{3} \mathrm{PO}_{4}$ per polymer repeat unit the conductivity at $160{ }^{\circ} \mathrm{C}$ increases from around $0.07 \mathrm{~S} \mathrm{~cm}^{-1}$ under dry conditions to $0.12 \mathrm{~S} \mathrm{~cm}^{-1}$ under fully humidified atmosphere. ${ }^{271}$

From a mechanistic point of view, the proton conduction in $\mathrm{H}_{3} \mathrm{PO}_{4}$ has been understood as a predominating Grotthuss-type structure diffusion process, where reorganization of the hydrogen bond network results in proton transport on longer length scales. ${ }^{293}$ The NMR studies by Suarez et al. ${ }^{294}$ support that this is the predominating conductivity mechanism in the $\mathrm{H}_{3} \mathrm{PO}_{4}-\mathrm{PBI}$ system as well. However, recent fundamental studies show that the Grotthuss-type conductivity mechanism 
only prevails in a narrow temperature and composition range. ${ }^{295,296}$ Moving away from this range leads to an increasing contribution from vehicular migration of phosphoric oxoacid species in electric fields, and ultimately redistribution of the acid. ${ }^{297-301}$

From a technological point of point, the redistribution of the acid is a formidable challenge and represents a major degradation mode when the $\mathrm{H}_{3} \mathrm{PO}_{4}-\mathrm{PBI}$ system is used as electrolyte in fuel cells. ${ }^{5,302}$ Theoretical studies by means of density functional theory calculations suggest that headhead coupled polybenzimidazoles binds the acid stronger, which would reduce the acid mobility, ${ }^{303}$ but it remains to be confirmed experimentally. One approach that has been verified experimentally to improve the acid retention characteristics and extend the operating temperature window to beyond $200^{\circ} \mathrm{C}$ is based on the introduction of an inorganic filler within the polymer matrix, such as silica, which forms phosphosilicates in situ. ${ }^{304,305}$ The use of a layered structure with a highly $\mathrm{H}_{3} \mathrm{PO}_{4}$ doped $m$-PBI core with barrier layers of $m$ - $\mathrm{PBI}$ with a lower $\mathrm{H}_{3} \mathrm{PO}_{4}$ has also been explored as a strategy to improve acid retention, but the durability improvements was found to be primarily due to a higher acid inventory. ${ }^{306}$ However, the most well-documents strategy to extend the lifetime of fuel cells based on the $\mathrm{H}_{3} \mathrm{PO}_{4}-\mathrm{PBI}$ electrolyte systems is to improve the dimensional stability of the polymer electrolyte membrane by crosslinking ${ }^{5,133,224}$ or by making use of creep resistant PBI chemistries. ${ }^{4}$

\section{Poly(dialkyl benzimidazolium)s}

As discussed in section 2.3, the $N$-functionalization of PBI is relatively straightforward and it can be carried out by an initial activation of the PBI with a strong, non-nucleophilic, base followed by addition of an electrophile, such as an alkyl or benzyl halide. The first $N$-functionalization occurs readily and practically exclusively at the imidazole amine groups. Further functionalization of the imidazole imine group usually proceeds slower and often require some heating. As shown in Scheme 7, the second alkylation step yields the corresponding poly(di(alkyl/aryl) benzimidazolium) iodide in nearly quantitative yield. ${ }^{307}$ Henkensmeier et al. ${ }^{308}$ and Thomas et al. ${ }^{309}$ carried out the conversion of $m$-PBI to the corresponding poly(dimethyl benzimidazolium) iodide in one step by activating $m$-PBI with a metal hydride ( $\mathrm{LiH}$ or NaH) in dry NMP followed by addition of excess iodomethane, and showed that alkylated PBIs can be used as anion exchange membranes. Henkensmeier et al. ${ }^{110}$ extended the methodology to an electron-rich PBI derived from $\mathrm{DAB}$ and 4,4'-dicarboxylic acid-diphenylether (Table 1; Entry 13), using $\mathrm{NaH}$ for the 
activation and obtained the corresponding poly(dimethyl benzimidazolium) iodide with $87 \%$ methylation.

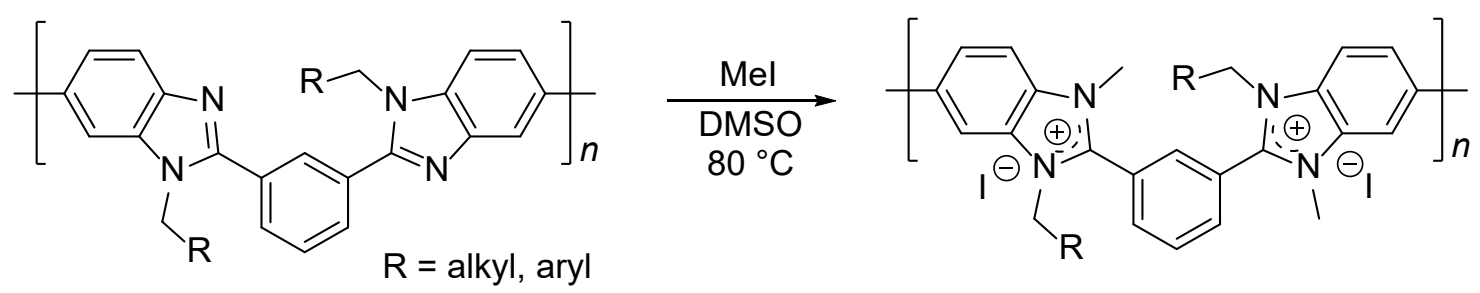

Scheme 7 Formation of alkyl/aryl poly(di(alkyl/aryl) benzimidazolium) iodide ${ }^{307}$.

Due to the changed chemistry, poly(dimethyl benzimidazolium) is only partially soluble in DMAc and NMP, and is therefore cast from DMSO. Through subsequent ion exchange steps, the poly(dimethyl benzimidazolium) was obtained in different salt forms. The $\mathrm{Cl}^{-}, \mathrm{Br}^{-}, \mathrm{I}^{-}, \mathrm{NO}_{3}{ }^{-}$and $\mathrm{HCO}_{3}{ }^{-}$forms showed water uptakes corresponding to $167,2,2,3$ and $5 \mathrm{H}_{2} \mathrm{O}$ per ionic group, respectively, i.e. $332,4,4,6$ and $10 \mathrm{H}_{2} \mathrm{O}$ per polymer repeat unit, respectively. ${ }^{309}$ The measured ion exchange capacity was in a range of 2.97-4.16 meq. $\mathrm{g}^{-1}$ and the anion conductivity ranged from $0.32-0.85 \mathrm{mS} \mathrm{cm}^{-1}$. Due to the high water uptake, the $\mathrm{Cl}^{-}$form swells strongly in salt solutions and dissolve instantaneously in pure water. For use in $\mathrm{HCl}$ based batteries, dibromoxylene crosslinked PBI membranes were prepared and methylated heterogeneously by immersing the membranes in water containing $\mathrm{KOH}$ and a few drops of iodomethane. ${ }^{310}$ The poly(dimethyl benzimidazolium) in the $\mathrm{I}^{-}$form prepared by Henkensmeier et al. ${ }^{308}$ showed water uptake corresponding to $6 \mathrm{H}_{2} \mathrm{O}$ per ionic group and an $\mathrm{I}^{-}$conductivity of $4.5 \mathrm{mS} \mathrm{cm}^{-1}$. Both groups attempted to exchange the $\mathrm{I}^{-}$ counter anion with $\mathrm{OH}^{-}$, which resulted in instant decomposition of the polymer and disintegration of the material. As shown in Scheme 8, this is due to the nucleophilic addition of $\mathrm{OH}^{-}$at the benzimidazolium $\mathrm{C} 2$ position, resulting in hydrolytic ring opening to an amine-amide. While these steps can be reversed upon acidification, ${ }^{110}$ the subsequent chain scission due to hydrolysis of the formed amide is irreversible. ${ }^{110,308,309}$ 


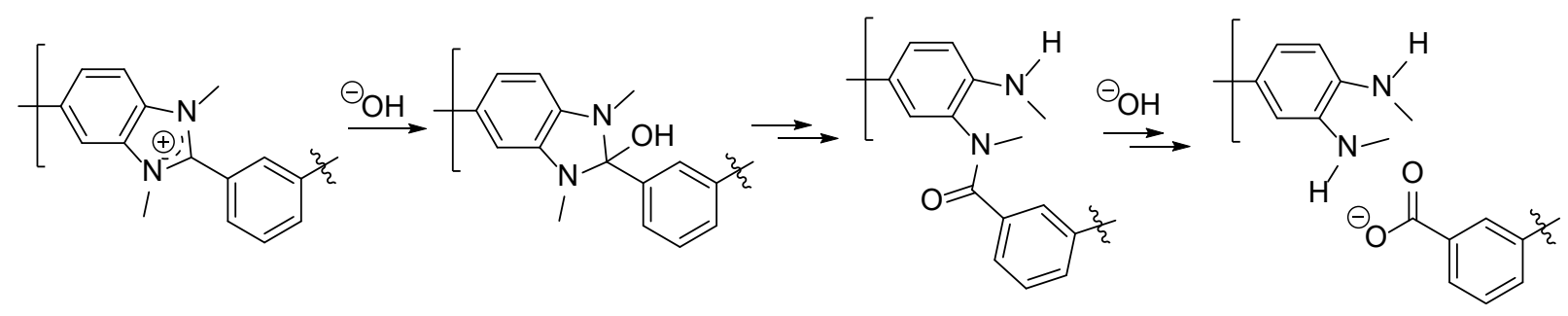

Scheme 8 Suggested degradation pathway of poly(dimethyl benzimidazolium) under alkaline conditions.

As a degradation mitigation strategy of the poly(dimethyl benzimidazolium) under alkaline conditions, Henkensmeier et al. ${ }^{110}$ suggested to increase the electron density in the system by substituting the phenyl moiety linking the two imidazolium groups in a repeat unit by phenyloxyphenyl, effectively separating the two charges (see Table 1; Entry 13 and 14). As expected, this was found to reduce the degradation rate. ${ }^{110,311}$ The dimethylbenzimidazolium containing ether linkages showed better stability in the hydroxide form than the corresponding dimethylbenzimidazolium derivatives containing sulfone (Table 1; Entry 12) linkages or partially fluorinated (Table 1; Entry 42) segments. ${ }^{312}$ Furthermore, the poly(dibenzyl benzimidazolium) hydroxide showed better stability than the dimethylated counterpart. ${ }^{313}$ Another attempt to improve the stability was to incorporate longer aliphatic segments in the structure (Table 1; Entry 9), but the concept did not circumvent the major degradation mode. ${ }^{98}$

A more effective stabilization approach was reported by Thomas et al., ${ }^{90}$ who introduced methyl substituents on the $m$-phenylene group adjacent to the polybenzimidazolium $\mathrm{C} 2$ position (see Table 1; Entry 6). After $N$-methylation, as shown in Scheme 9, the dihedral angle between the benzimidazoliums and the phenylenes was changed so that the methyl groups on the phenylene moieties were positioned above and under the benzimidazolium plane and sterically protected the benzimidazolium $\mathrm{C} 2$ position from nucleophilic attack. The result was a dramatically improved stability under alkaline conditions, and it showed no structural changes after treatment for 10 days in $2 \mathrm{~mol} \mathrm{~L}^{-1}$ aqueous $\mathrm{KOH}$ at $60{ }^{\circ} \mathrm{C}$. The ionene was soluble in water, but the swelling could effectively be reduced by blending with $m$-PBI to give mechanically robust films with hydroxide conductivity up to $13 \mathrm{mS} \mathrm{cm}^{-1}$, which will be further discussed. 


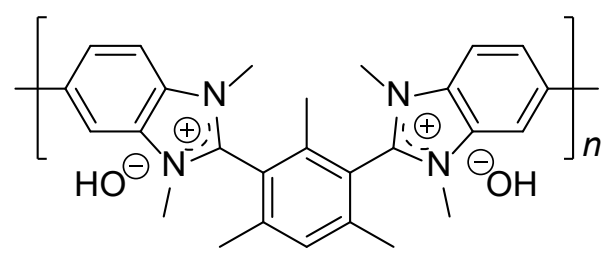

Scheme 9 Chemical structure of the first sterically protected poly(dimethyl benzimidazolium) ionene in the hydroxide form. ${ }^{90}$

The concept has been further developed during the last few years to tailor the properties and to reduce the swelling in water by e.g. controlling the degree of $N$-methylation ${ }^{92,}{ }^{94}$ or by crosslinking. ${ }^{93}$ Furthermore, Ma et al. ${ }^{155}$ introduced an even more bulky $p$-phenylene link in the polymer, containing four phenyl substituents. The base polymer was obtained from randomcopolymerization with excess isophthalic acid (see Table 3; Entry 11), which implies that a large fraction of unprotected benzimidazolium $\mathrm{C} 2$ carbons are exposed to the hydroxide ions. However, good stability was demonstrated in $1 \mathrm{~mol} \mathrm{~L}^{-1} \mathrm{NaOH}$ at $80^{\circ} \mathrm{C}$ for $800 \mathrm{~h}$, which seems supported by the model system studies by Wright et al. ${ }^{314}$ on $m$-terphenyl-protected benzimidazolium.

The initially reported hydroxide conductivities were rather low in despite the high IEC values ( 4.4 meq. $\mathrm{g}^{-1}$ for the material shown in Scheme 9). This seems to be the effect of rapid $\mathrm{CO}_{2}$ absorption from air, changing the hydroxide ions into less mobile (bi)carbonate ions. A membrane derived from a structural extension of the initial concept (see Table 1; Entry 7), immersed in water, showed a conductivity of just $25 \mathrm{mS} \mathrm{cm}{ }^{-1} \cdot{ }^{92}$ However, by applying a direct current through the membranes between the platinum electrodes used for in-plane conductivity measurement, the hydroxide ions obtained by water electrolysis at the electrodes flushed the carbonates away, and a conductivity of around $100 \mathrm{mS} \mathrm{cm}^{-1}$ at $40{ }^{\circ} \mathrm{C}$ could be measured. ${ }^{315}$ This conductivity is similar to that of commercial Nafion membranes, and, in combination with the high alkaline stability of sterically protected poly(dimethyl benzimidazolium), this class of polymers is of high interest for alkaline energy applications like fuel cells or electrolyzers.

Computational approaches are now being employed to explore how the poly(dimethyl benzimidazolium) structure affect e.g. chain conformation, which could lead to a better understanding of the structure-properties relationships and point out the most rational development strategies. ${ }^{316}$ The significant advancements in backbone stabilization may also reveal new 
challenges on the device level that need to be addressed to further extend lifetime (mitigating dealkylation), improve mechanical robustness and optimizing the hydration characteristics. ${ }^{317}$

\section{Polybenzimidazolides}

As discussed in section 2.3, the first step in the $N$-functionalization of PBIs is the deprotonation with a strong non-nucleophilic base, such as alkali metal hydrides, to form a polybenzimidazolide. However, aqueous solutions of alkali metal hydroxides are also sufficiently basic to subtract protons from the benzimidazole groups, to form a polybenzimidazolide, as shown in Scheme 10.

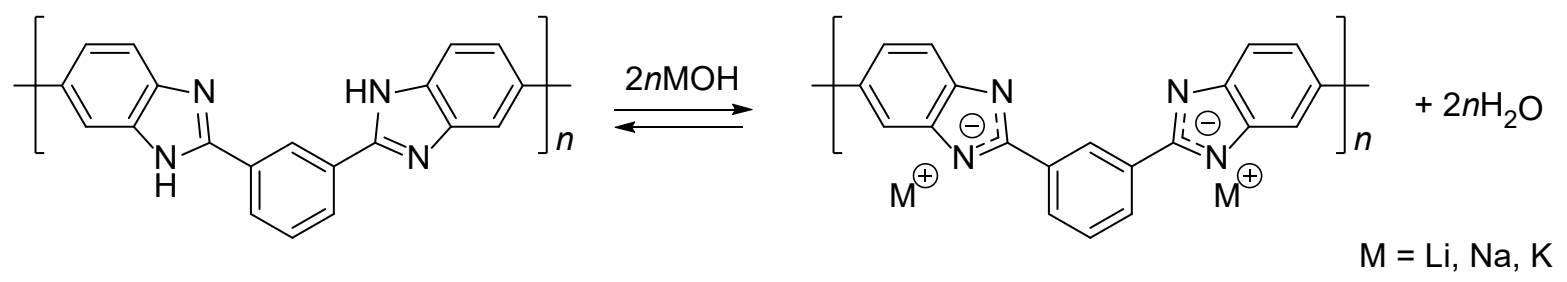

Scheme 10 Formation of polybenzimidazolide under aqueous alkaline conditions.

The position of the equilibrium depends on the $\mathrm{pH}$ of the solution, i.e. the concentration of the alkali metal hydroxide. The $\mathrm{p} K_{\mathrm{a}}$ value of benzimidazole is $12.8^{318}$ and assuming that the $\mathrm{p} K_{\mathrm{a}}$ value applies for $m$-PBI as well, the polybenzimidazolide form should predominate at $\mathrm{KOH}$ concentrations higher than $0.6 \mathrm{~mol} \mathrm{~L}^{-1} \cdot{ }^{9}$ However, in the form of thin films, $m$-PBI undergoes complete ionization at $\mathrm{KOH}$ concentrations in the range $15-20 \mathrm{wt}$ \%, which corresponds to 3.0-4.2 mol L ${ }^{-1}{ }^{259}$ This is suggested to be due to the low uptake of aqueous $\mathrm{KOH}$ in the lower concentration range. ${ }^{319}$ However, following complete ionization, the intermolecular hydrogen bonding is released, which allows for further uptake of water and $\mathrm{KOH}$. The volume swelling that follows the benzimidazolide formation is highly anisotropic, and seen as a dramatic increase in thickness but a reduction of the surface area. ${ }^{255,259,319-321}$ The aqueous $\mathrm{KOH}$ uptake is a fast process, and the equilibrium is reached within seconds to minutes at room temperature, although the structural evolution that is correlated to the macroscopic swelling behavior occurs on a time scale of hours. ${ }^{255}$ The resulting material is a ternary system based on the polymer, water and $\mathrm{KOH}$ and was initially explored as an alectrolyte system for alkaline fuel cells. ${ }^{6}$

For $m$-PBI, the equilibrium composition of the ternary system at different $\mathrm{KOH}$ concentration is summarized in Figure 4 a, normalized as the number of $\mathrm{H}_{2} \mathrm{O}$ molecules and $\mathrm{KOH}$ 
ion pairs per polymer repeat unit. ${ }^{259}$ It can be seen that the water and $\mathrm{KOH}$ uptake increases with increasing $\mathrm{KOH}$ concentration of the surrounding solution, until the concentration reaches $25 \mathrm{wt} . \%$ (5.5 $\mathrm{mol} \mathrm{L}^{-1}$ at room temperature). At higher $\mathrm{KOH}$ concentrations, the water concentration in the ternary system goes down, also resulting in lower water uptake. It should be remarked that the exchange of a hydrogen with potassium during the polybenzimidazolide formation (see Scheme 10) results in an increased molecular weight for the polymer repeat units, which is not compensated for in the presented data. 9, 259

a)

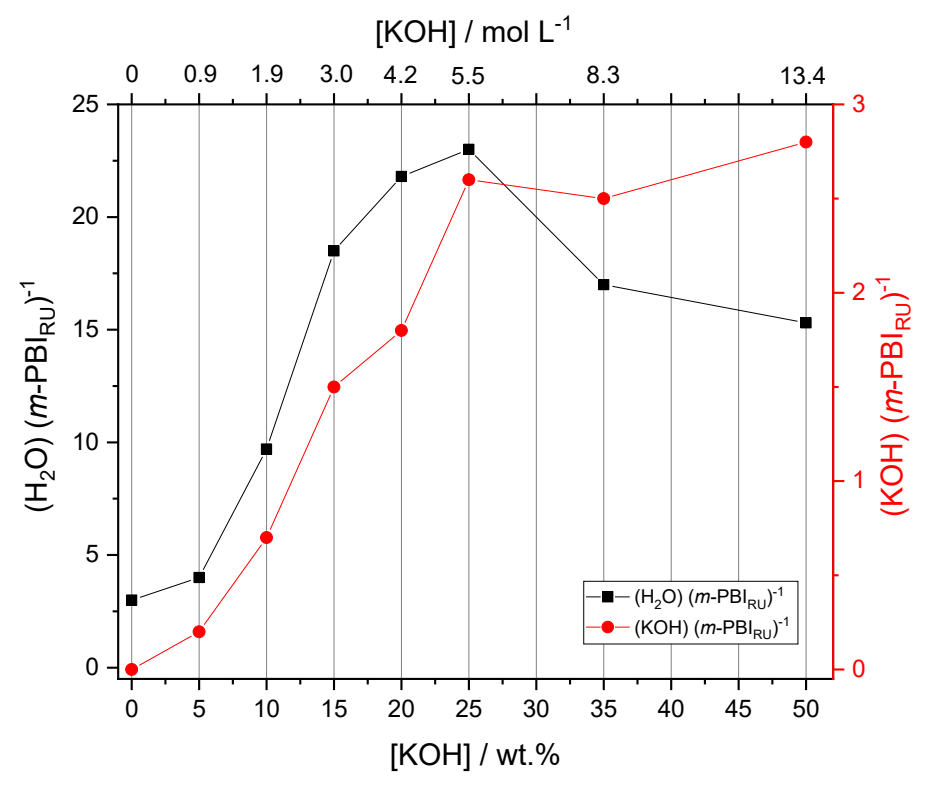

b) 


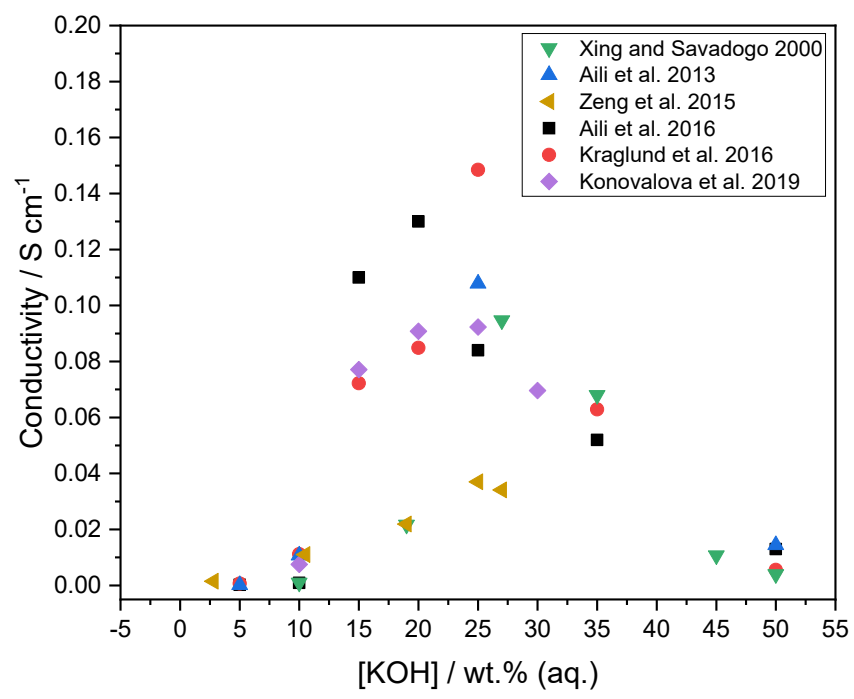

Figure 4 (a) Water and $\mathrm{KOH}$ content per $m$-PBI repeat unit after equilibration in $0-50 \mathrm{wt} . \%$ $\mathrm{KOH}$ at room temperature 255 ; (b) Conductivity based on literature data reported by Xing and Savadogo, ${ }^{6}$ Aili et al., ${ }^{9,259}$ Kraglund et al., ${ }^{322}$ Konovalova et al. ${ }^{321}$ and Zeng et al. ${ }^{7,319}$

Another consequence of the polybenzimidazolide formation is the change in solubility. For example, the polybenzimidazolide derived from $m$-PBI readily dissolves in ethanol when a few weight percent of $\mathrm{NaOH}$ or $\mathrm{KOH}$ is added. ${ }^{164}$ The alkaline ethanol solution of the polybenzimidazolide can be used for further processing by e.g. electrospinning. ${ }^{323}$ As mentioned in section 4, the sterically protected poly(dimethylbenzimidazolium) hydroxide was soluble in water, but complexing with a polybenzimidazolide formed under alkaline conditions proved an efficient approach to balance the swelling, ${ }^{90}$ as shown in Scheme 11.

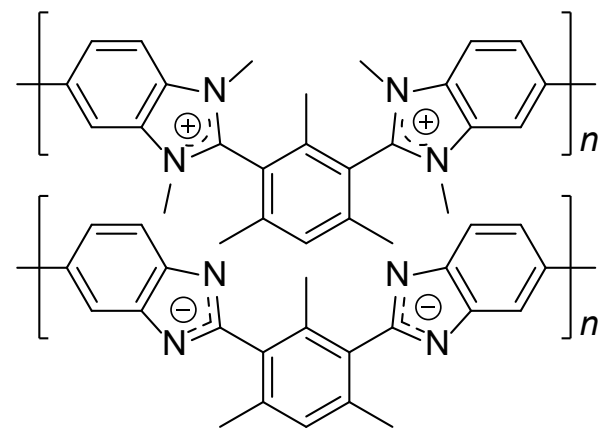


Scheme 11 Ionic pairing of poly(dimethyl polybenzimidazolium) and the corresponding polybenzimidazolide as described by Thomas et al. ${ }^{90}$

The room temperature ion conductivity data for the ternary $\mathrm{H}_{2} \mathrm{O} / \mathrm{KOH} / m$-PBI system as reported in the literature are compiled in Figure $4 \mathrm{~b}$. The conductivity peak coincides with the maximum in water uptake at around $25 \mathrm{wt} . \% \mathrm{KOH}$ in the surrounding solutions and reach $0.04-0.14 \mathrm{~S} \mathrm{~cm}^{-1}$ depending on the measurement technique and the particular experimental conditions. One of the reasons for the relatively large scattering in the reported conductivity data could be the structural evolution of the membrane over time, which would affect the percolation and the ionic pathways in the material. ${ }^{255}$ However, the remarkably high ion conductivity of $m-\mathrm{PBI}$ in aqueous $\mathrm{KOH}$ in combination with its gas tightness and mechanical robustness point out a new way of constructing energy- and cost efficient electrolyzers for hydrogen production. ${ }^{10}$ It is important to note that water must to be present to dissociate the $\mathrm{KOH}$ within the membrane, which is not a problem in electrolysis cells when the cell is fed continuously with electrolyte, but could be problematic when operated in fuel cell mode.

The conductivity behavior of $m$-PBI has also been explored in aqueous $\mathrm{LiOH}^{6}$ and $\mathrm{NaOH},{ }^{6}$, ${ }^{324}$ but the conductivity is lower than in aqueous $\mathrm{KOH}$ due to the lower intrinsic conductivity of aqueous $\mathrm{LiOH}$ and $\mathrm{NaOH}$ and lower uptake of the aqueous hydroxide solutions. The conductivity of $m$-PBI in aqueous $\mathrm{NaOH}$ follows the same trend as in $\mathrm{KOH}$ and peaks at around $0.015 \mathrm{~S} \mathrm{~cm}^{-1}$ in $7 \mathrm{~mol} \mathrm{~L}^{-1}$ at room temperature. ${ }^{325}$ Sulfonation of $m$-PBI promotes the electrolyte uptake at lower concentrations of the alkali metal hydroxide, which in turn results in enhanced ion conductivity in the lower concentration range. ${ }^{326}$

Compared with poly(dialkyl benzimidazoliums), the polybenzimidazolide form shows better intrinsic resistance towards nucleophilic attack, due the electron rich aromatic system and high electron density around the benzimidazolide $\mathrm{C} 2$ position. In chemical stability tests, $m$-PBI was proven fully stable in $5 \mathrm{wt} . \% \mathrm{KOH}$ at close to $90^{\circ} \mathrm{C}$ for 6 months. ${ }^{167}$ However, increasing the $\mathrm{KOH}$ concentration resulted in gradual degradation of the polymer and the degradation rate increased with increasing $\mathrm{KOH}$ concentration, as monitored by inherent viscosity measurements in combination with size exclusion chromatography. ${ }^{167}$ Steric protection of the polybenzimidazolide $\mathrm{C} 2$ position has been explored in the context of $\mathrm{KOH}$ (aq.) imbibed membranes as well, but has not proven sufficiently effective to drastically suppress the 
degradation. $^{91}$ The predominant degradation mechanism likely differs from that of the poly(dialkylbenzimidazolium), and detailed mapping of the degradation pathway is therefore needed for the development of rational degradation mitigation strategies.

\section{Concluding remarks and prospects for further development}

New application areas in emerging electrochemical conversion technologies and separation processes have been main drivers for the tremendous development of new PBI chemistries during the past two decades. A large variety of PBI structures have been reported in the literature, primarily from homogenous solution polymerization in polyphosphoric acid or Eaton's reagent. The latter give access to PBIs derived from e.g. larger ether containing dicarboxylic acids, which cannot be obtained in polyphosphoric acid due to solubility limitations. The majority of the structures have been obtained by varying the dicarboxylic acid monomer, which likely is a result of the large variety of dicarboxylic acids that are available on a commercial basis. Many examples of random copolymers obtained from mixtures of different dicarboxylic acids at different ratios have also been reported in the literature. PBIs derived from alternative tetra-amines are considerable less common, likely because substantial synthetic efforts are required to obtain sufficient monomer quantities and qualities for polymerization. The molecular weight determination of PBIs is typically done by a Mark-Houwink correlation based on viscosity data in sulfuric acid, although the sets of Mark-Houwink constants available in the literature have been obtained in a low molecular weight range. Size exclusion chromatography tend to overestimate the molecular weight, due to the agglomeration of the polymer in organic solvents.

Among the polymer modification concepts, $N$-coupling to the benzimidazole groups has been extensively explored for grafting as well as for crosslinking. The reaction proceeds smoothly in the presence of a base catalyst, but also occur without base catalyst at elevated temperatures or when reactive electrophiles are used. The methodology can be extended to produce cationic ionenes in the form of poly(dialkyl benzimidazolium)s, by reacting the $N$-functionalized polybenzimidazole with e.g. an alkyl iodide. The poly(dialkyl benzimidazolium)s show good stability under neutral conditions, but rapidly degrade in alkaline environment unless the benzimidazolium C2 position is protected from nucleophilic attack. Steric hindrance is a particularly successful degradation mitigation strategy in this connection. 
The PBIs react quantitatively even with relatively weak protic acids, such as $\mathrm{H}_{3} \mathrm{PO}_{4}$, to form protic polybenzimidazoliums. The formation of cationic protic polybenzimidazolium ionenes and the excessive acid uptake result in dramatically changed physicochemical properties. The $\mathrm{H}_{3} \mathrm{PO}_{4}$ exerts a plasticizing effect, but supports proton conductivity of $>10 \mathrm{mS} \mathrm{cm}^{-1}$ at acid doping levels corresponding to $>5 \mathrm{H}_{3} \mathrm{PO}_{4}$ per polymer repeat unit at temperatures at temperatures up to $200{ }^{\circ} \mathrm{C}$. Similarly, exposing PBI to a strongly alkaline solution, such as aqueous $\mathrm{KOH}$, results in deprotonation of the benzimidazole groups to form an anionic ionene in the form of a polybenzimidazolide. As a result, the physicochemical properties of the material change significantly depending and the excess aqueous $\mathrm{KOH}$ within the structure can support remarkably high ion conductivity, provided that water is present to keep the ions solvated.

To conclude, significant progress has been achieved in the field of PBI chemistry and a voluminous catalogue of synthetic routes to vastly different structure derivatives has developed over the years. The application scope of PBI is continuously broadened, and emerging applications introduce new requirements in terms of stability and function. While $m$-PBI still serves as the state-of-the-art and benchmarking material, the search for new structures should be guided by particular materials requirements, which in the end are highly application dependent.

\section{Acknowledgement}

This work was financially supported by Innovation Fund Denmark (DanFlow), the Danish EUDP program (COBRA-Drive) and the National Natural Science Foundation of China (51603031). DH thank also NRF/EU H2020 (Newly).

\section{References}

1. H. Vogel and C. S. Marvel, Journal of Polymer Science, 1961, 50, 511-539.

2. E. W. Neuse, Advances in Polymer Science, 1982, 47, 1-42.

3. T. S. Chung, J. Macromol. Sci.-Rev. Macromol. Chem. Phys., 1997, C37, 277-301.

4. A. T. Pingitore, F. Huang, G. Qian and B. C. Benicewicz, ACS Applied Energy Materials, 2019, 2, 1720-1726.

5. T. Søndergaard, L. N. Cleemann, H. Becker, D. Aili, T. Steenberg, H. A. Hjuler, L. Seerup, Q. Li and J. O. Jensen, Journal of Power Sources, 2017, 342, 570-578.

6. B. Xing and O. Savadogo, Electrochemistry Communications, 2000, 2, 697-702. 
7. L. Zeng, T. S. Zhao, L. An, G. Zhao and X. H. Yan, Energy \& Environmental Science, 2015, 8, 2768-2774.

8. D. Aili, M. K. Hansen, C. Pan, Q. Li, E. Christensen, J. O. Jensen and N. J. Bjerrum, International Journal of Hydrogen Energy, 2011, 36, 6985-6993.

9. D. Aili, M. K. Hansen, R. F. Renzaho, Q. Li, E. Christensen, J. O. Jensen and N. J. Bjerrum, Journal of Membrane Science, 2013, 447, 424-432.

10. M. R. Kraglund, M. Carmo, G. Schiller, S. A. Ansar, D. Aili, E. Christensen and J. O. Jensen, Energy \& Environmental Science, 2019, 12, 3313-3318.

11. J. V. Jayakumar, A. Gulledge, J. A. Staser, C.-H. Kim, B. C. Benicewicz and J. W. Weidner, ECS Electrochemistry Letters, 2012, 1, F44-F48.

12. X. L. Zhou, T. S. Zhao, L. An, L. Wei and C. Zhang, Electrochimica Acta, 2015, 153, 492498.

13. Z. Yuan, Y. Duan, H. Zhang, X. Li, H. Zhang and I. Vankelecom, Energy and Environmental Science, 2016, 9, 441-447.

14. C. Noh, M. Jung, D. Henkensmeier, S. W. Nam and Y. Kwon, ACS Applied Materials \& Interfaces, 2017, 9, 36799-36809.

15. P. Leung, D. Aili, Q. Xu, A. Rodchanarowan and A. A. Shah, Sustainable Energy \& Fuels, 2018, 2, 2252-2259.

16. Z. Yuan, Y. Duan, T. Liu, H. Zhang and X. Li, iScience, 2018, 3, 40-49.

17. W. Lee, M. Jung, D. Serhiichuk, C. Noh, G. Gupta, C. Harms, Y. Kwon and D. Henkensmeier, Journal of Membrane Science, 2019, 591, 117333.

18. B. Shanahan, T. Böhm, B. Britton, S. Holdcroft, R. Zengerle, S. Vierrath, S. Thiele and M. Breitwieser, Electrochemistry Communications, 2019, 102, 37-40.

19. F. J. Oldenburg, E. Nilsson, T. J. Schmidt and L. Gubler, Chemsuschem, 2019, 12, 26202627.

20. J. Y. Wang, Y. He, Q. Wu, Y. F. Zhang, Z. Y. Li, Z. H. Liu, S. K. Huo, J. M. Dong, D. L. Zeng and H. S. Cheng, Sci Rep, 2019, 9, 10.

21. G. H. Sun, B. X. Liu, H. Q. Niu, F. Y. Hao, N. J. Chen, M. Y. Zhang, G. F. Tian, S. L. Qi and D. Z. Wu, Journal of Membrane Science, 2020, 595, 8.

22. R. Bouchet, E. Siebert and G. Vitter, Journal of the Electrochemical Society, 1997, 144, L95-L97. 
23. R. Bouchet, E. Siebert and G. Vitter, Journal of The Electrochemical Society, 2000, 147, 3125-3130.

24. S. Rosini and E. Siebert, Electrochimica Acta, 2004, 49, 525-536.

25. T. Kwon, J.-W. Lee, H. Cho, D. Henkensmeier, Y. Kang, S. M. Hong and C. M. Koo, Sensors and Actuators B: Chemical, 2015, 214, 43-49.

26. K. A. Perry, G. A. Eisman and B. C. Benicewicz, Journal of Power Sources, 2008, 177, 478-484.

27. F. Huang, A. T. Pingitore and B. C. Benicewici, Journal of the Electrochemical Society, 2020, 167, 10 .

28. M. Thomassen, E. Sheridan and J. Kvello, Journal of Natural Gas Science and Engineering, 2010, 2, 229-234.

29. F. Huang, A. T. Pingitore, T. Campbell, A. Knight, D. Johnson, L. G. Johnson and B. C. Benicewicz, Acs Applied Energy Materials, 2020, 3, 614-624.

30. S. C. Kumbharkar, Y. Liu and K. Li, Journal of Membrane Science, 2011, 375, 231-240.

31. X. Li, R. P. Singh, K. W. Dudeck, K. A. Berchtold and B. C. Benicewicz, Journal of Membrane Science, 2014, 461, 59-68.

32. L. Zhu, M. T. Swihart and H. Lin, Journal of Materials Chemistry A, 2017, 5, 1991419923.

33. S. Y. Kong, D. H. Kim, D. Henkensmeier, H.-J. Kim, H. C. Ham, J. Han, S. P. Yoon, C. W. Yoon and S. H. Choi, Separation and Purification Technology, 2017, 179, 486-493.

34. L. X. Zhu, M. T. Swihart and H. Q. Lin, Energy \& Environmental Science, 2018, 11, 94100.

35. C.-H. Huang and Y.-L. Liu, RSC Advances, 2017, 7, 38360-38366.

36. K. Y. Wang, Y. C. Xiao and T. S. Chung, Chemical Engineering Science, 2006, 61, 58075817.

37. J. S. Wainright, J. T. Wang, D. Weng, R. F. Savinell and M. Litt, Journal of the Electrochemical Society, 1995, 142, L121-L123.

38. Q. Li, R. H. He, J. O. Jensen and N. J. Bjerrum, Chemistry of Materials, 2003, 15, 48964915.

39. J. Mader, L. Xiao, T. J. Schmidt and B. C. Benicewicz, in Fuel Cells Ii, 2008, vol. 216, pp. $63-124$. 
40. Q. Li, J. O. Jensen, R. F. Savinell and N. J. Bjerrum, Progress in Polymer Science, 2009, 34, 449-477.

41. J. A. Asensio, E. M. Sanchez and P. Gomez-Romero, Chemical Society Reviews, 2010, 39, 3210-3239.

42. E. Quartarone and P. Mustarelli, Energy \& Environmental Science, 2012, 5, 6436-6444.

43. H. W. Zhang and P. K. Shen, Chemical Reviews, 2012, 112, 2780-2832.

44. A. Chandan, M. Hattenberger, A. El-Kharouf, S. F. Du, A. Dhir, V. Self, B. G. Pollet, A. Ingram and W. Bujalski, Journal of Power Sources, 2013, 231, 264-278.

45. R. Zeis, Beilstein Journal of Nanotechnology, 2015, 6, 68-83.

46. S. S. Araya, F. Zhou, V. Liso, S. L. Sahlin, J. R. Vang, S. Thomas, X. Gao, C. Jeppesen and S. K. Kær, International Journal of Hydrogen Energy, 2016, 41, 21310-21344.

47. D. Aili, D. Henkensmeier, S. Martin, B. Singh, Y. Hu, J. O. Jensen, L. N. Cleemann and Q. Li, Electrochemical Energy Reviews, 2020.

48. H. Vogel and C. S. Marvel, Journal of Polymer Science Part a-General Papers, 1963, 1, $1531-\&$.

49. Y. Iwakura, Y. Imai and K. Uno, Journal of Polymer Science Part a-General Papers, 1964, 2, 2605-2615.

50. J. A. Asensio, S. Borros and P. Gomez-Romero, Journal of Polymer Science Part A: Polymer Chemistry, 2002, 40, 3703-3710.

51. J. A. Asensio, S. Borros and P. Gomez-Romero, Electrochemistry Communications, 2003, 5, 967-972.

52. J. A. Asensio, S. Borro and P. Gomez-Romero, Journal of the Electrochemical Society, 2004, 151, A304-A310.

53. J. A. Asensio, S. Borros and P. Gomez-Romero, Journal of Membrane Science, 2004, 241, 89-93.

54. A. L. Gulledge, B. Gu and B. C. Benicewicz, Journal of Polymer Science Part A: Polymer Chemistry, 2012, 50, 306-313.

55. A. L. Gulledge, X. M. Chen and B. C. Benicewicz, Journal of Polymer Science Part aPolymer Chemistry, 2014, 52, 619-628.

56. J. A. Asensio and P. Gomez-Romero, Fuel Cells, 2005, 5, 336-343. 
57. H. J. Xu, K. C. Chen, X. X. Guo, J. H. Fang and J. Yin, Journal of Polymer Science Part A: Polymer Chemistry, 2007, 45, 1150-1158.

58. J. Weber, K.-D. Kreuer, J. Maier and A. Thomas, Advanced Materials, 2008, 20, $2595-$ 2598.

59. A. Kirkebæk, D. Aili, D. Henkensmeier, J. O. Jensen and Q. Li, Macromol. Mater. Eng., 2017, DOI: 10.1002/mame.201700347, 1700347.

60. Q. Li, R. H. He, J. O. Jensen and N. J. Bjerrum, Fuel Cells, 2004, 4, 147-159.

61. J. S. Yang, L. N. Cleemann, T. Steenberg, C. Terkelsen, Q. F. Li, J. O. Jensen, H. A. Hjuler, N. J. Bjerrum and R. H. He, Fuel Cells, 2014, 14, 7-15.

62. J. Lobato, P. Cañizares, M. A. Rodrigo, J. J. Linares and G. Manjavacas, Journal of Membrane Science, 2006, 280, 351-362.

63. R. H. He, B. Y. Sun, J. S. Yang and Q. T. Che, Chem. Res. Chin. Univ., 2009, 25, 585-589.

64. J. S. A. Yang, R. H. He, Q. T. Che, X. L. Gao and L. L. Shi, Polym. Int., 2010, 59, 16951700.

65. P. E. Eaton, G. R. Carlson and J. T. Lee, The Journal of Organic Chemistry, 1973, 38, 4071-4073.

66. M. Ueda, M. Sato and A. Mochizuki, Macromolecules, 1985, 18, 2723-2726.

67. H. J. Kim, S. J. An, J. Y. Kim, J. K. Moon, S. Y. Cho, Y. C. Eun, H. K. Yoon, Y. Park, H. J. Kweon and E. M. Shin, Macromol. Rapid Commun., 2004, 25, 1410-1413.

68. J. Higgins and C. S. Marvel, Journal of Polymer Science Part a-1-Polymer Chemistry, 1970, 8, 171-\&.

69. K. J. Fishel, A. L. Gulledge, A. T. Pingitore, J. P. Hoffman, W. P. Steckle and B. C. Benicewicz, Journal of Polymer Science Part a-Polymer Chemistry, 2016, 54, 1795-1802.

70. E. K. Kim, S. Y. Lee, S. Y. Nam, S. J. Yoo, J. Y. Kim, J. H. Jang, D. Henkensmeier, H. J. Kim and J. C. Lee, Polym. Int., 2017, 66, 1812-1818.

71. F. L. Hedberg and C. S. Marvel, Journal of Polymer Science Part a-Polymer Chemistry, 1974, 12, 1823-1828.

72. J. Weber, ChemSusChem, 2010, 3, 181-187.

73. G. Q. Qian, D. W. Smith and B. C. Benicewicz, Polymer, 2009, 50, 3911-3916.

74. X. Li, G. Qian, X. Chen and B. C. Benicewicz, Fuel Cells, 2013, 13, 832-842. 
75. J.-C. Chen, P.-Y. Chen, S.-W. Lee, G.-L. Liou, C.-J. Chen, Y.-H. Lan and K.-H. Chen, Reactive and Functional Polymers, 2016, 108, 122-129.

76. G. Qian and B. C. Benicewicz, Journal of Polymer Science Part A: Polymer Chemistry, 2009, 47, 4064-4073.

77. J. Fang, X. Lin, D. Cai, N. He and J. Zhao, Journal of Membrane Science, 2016, 502, 29 36.

78. X. Li, H. Ma, Y. Shen, W. Hu, Z. Jiang, B. Liu and M. D. Guiver, Journal of Power Sources, 2016, 336, 391-400.

79. J. Olvera-Mancilla, J. Palacios-Alquisira and L. Alexandrova, High Performance Polymers, 2018, 30, 699-709.

80. E. W. Neuse, M. S. Loonat and G. Rabilloud, Macromolecules, 1986, 19, 481-484.

81. E. W. Neuse and M. S. Loonat, Macromolecules, 1983, 16, 128-136.

82. N. Chen, H. Zhu, Y. Chu, R. Li, Y. Liu and F. Wang, Polymer Chemistry, 2017, 8, 13811392.

83. L. X. Xiao, H. F. Zhang, E. Scanlon, L. S. Ramanathan, E. W. Choe, D. Rogers, T. Apple and B. C. Benicewicz, Chemistry of Materials, 2005, 17, 5328-5333.

84. S. C. Kumbharkar, M. N. Islam, R. A. Potrekar and U. K. Kharul, Polymer, 2009, 50, $1403-$ 1413.

85. S. C. Kumbharkar, P. B. Karadkar and U. K. Kharul, Journal of Membrane Science, 2006, 286, 161-169.

86. S. C. Kumbharkar and U. K. Kharul, Journal of Membrane Science, 2010, 357, 134-142.

87. S. Yu, H. Zhang, L. Xiao, E. W. Choe and B. C. Benicewicz, Fuel Cells, 2009, 9, 318-324.

88. A. Carollo, E. Quartarone, C. Tomasi, P. Mustarelli, F. Belotti, A. Magistris, F. Maestroni, M. Parachini, L. Garlaschelli and P. P. Righetti, Journal of Power Sources, 2006, 160, 175 180.

89. K. Geng, Y. Li, Y. Xing, L. Wang and N. Li, Journal of Membrane Science, 2019, 586, 231-239.

90. O. D. Thomas, K. Soo, T. J. Peckham, M. P. Kulkarni and S. Holdcroft, Journal of the American Chemical Society, 2012, 134, 10753-10756.

91. D. Aili, A. G. Wright, M. R. Kraglund, K. Jankova, S. Holdcroft and J. O. Jensen, Journal of Materials Chemistry A, 2017, 5, 5055-5066. 
92. A. G. Wright and S. Holdcroft, ACS Macro Letters, 2014, 3, 444-447.

93. T. Weissbach, A. G. Wright, T. J. Peckham, A. Sadeghi Alavijeh, V. Pan, E. Kjeang and S. Holdcroft, Chemistry of Materials, 2016, 28, 8060-8070.

94. A. G. Wright, J. Fan, B. Britton, T. Weissbach, H.-F. Lee, E. A. Kitching, T. J. Peckham and S. Holdcroft, Energy \& Environmental Science, 2016, 9, 2130-2142.

95. X. Li, X. Chen and B. C. Benicewicz, Journal of Power Sources, 2013, 243, 796-804.

96. H. Pu, L. Wang, H. Pan and D. Wan, Journal of Polymer Science Part A: Polymer Chemistry, 2010, 48, 2115-2122.

97. R. S. Bhavsar, S. B. Nahire, M. S. Kale, S. G. Patil, P. P. Aher, R. A. Bhavsar and U. K. Kharul, Journal of Applied Polymer Science, 2011, 120, 1090-1099.

98. H. Cho, D. Henkensmeier, M. Brela, A. Michalak, J. H. Jang and K.-Y. Lee, Journal of Polymer Science Part B: Polymer Physics, 2017, 55, 256-265.

99. S. Kumar B, B. Sana, G. Unnikrishnan, T. Jana and S. Kumar K. S, Polymer Chemistry, 2020, 11, 1043-1054.

100. S. Yu and B. C. Benicewicz, Macromolecules, 2009, 42, 8640-8648.

101. M. A. Molleo, X. Chen, H. J. Ploehn and B. C. Benicewicz, Fuel Cells, 2015, 15, 150-159.

102. X. M. Chen, G. Q. Qian, M. A. Molleo, B. C. Benicewicz and H. J. Ploehn, Journal of Polymer Science Part B-Polymer Physics, 2015, 53, 1527-1538.

103. Q. Li, H. C. Rudbeck, A. Chromik, J. O. Jensen, C. Pan, T. Steenberg, M. Calverley, N. J. Bjerrum and J. Kerres, Journal of Membrane Science, 2010, 347, 260-270.

104. J. S. Yang, Q. F. Li, L. N. Cleemann, C. X. Xu, J. O. Jensen, C. Pan, N. J. Bjerrum and R. H. He, Journal of Materials Chemistry, 2012, 22, 11185-11195.

105. A. Sannigrahi, S. Ghosh, J. Lalnuntluanga and T. Jana, Journal of Applied Polymer Science, 2009, 111, 2194-2203.

106. T.-H. Kim, S.-K. Kim, T.-W. Lim and J.-C. Lee, Journal of Membrane Science, 2008, 323, 362-370.

107. J. Li, X. J. Li, Y. Zhao, W. T. Lu, Z. G. Shao and B. L. Yi, ChemSusChem, 2012, 5, 896900 .

108. Y. Kang, J. Zou, Z. Sun, F. Wang, H. Zhu, K. Han, W. Yang, H. Song and Q. Meng, International Journal of Hydrogen Energy, 2013, 38, 6494-6502. 
109. H. Dai, H. Zhang, H. Zhong, H. Jin, X. Li, S. Xiao and Z. Mai, Fuel Cells, 2010, 10, 754761.

110. D. Henkensmeier, H. R. Cho, H. J. Kim, C. N. Kirchner, J. Leppin, A. Dyck, J. H. Jang, E. Cho, S. W. Nam and T. H. Lim, Polymer Degradation and Stability, 2012, 97, 264-272.

111. L. Xiao, H. Zhang, T. Jana, E. Scanlon, R. Chen, E. W. Choe, L. S. Ramanathan, S. Yu and B. C. Benicewicz, Fuel Cells, 2005, 5, 287-295.

112. P. Mustarelli, E. Quartarone, S. Grandi, S. Angioni and A. Magistris, Solid State Ionics, 2012, 225, 228-231.

113. J. Yang, Y. Xu, L. Zhou, Q. Che, R. He and Q. Li, Journal of Membrane Science, 2013, 446, 318-325.

114. M. R. Berber and N. Nakashima, Journal of Membrane Science, 2019, 591, 117354.

115. G. Sun, K. Han, J. Yu, H. Zhu and Z. Wang, RSC Advances, 2016, 6, 91068-91076.

116. S.-K. Kim, T.-H. Kim, J.-W. Jung and J.-C. Lee, Polymer, 2009, 50, 3495-3502.

117. J.-K. Jang, T.-H. Kim, S. J. Yoon, J. Y. Lee, J.-C. Lee and Y. T. Hong, Journal of Materials Chemistry A, 2016, 4, 14342-14355.

118. Y. Guan, H. Pu, M. Jin, Z. Chang and A. D. Modestov, Fuel Cells, 2012, 12, 124-131.

119. H. Namazi and H. Ahmadi, Journal of Power Sources, 2011, 196, 2573-2583.

120. R. A. Potrekar, M. P. Kulkarni, R. A. Kulkarni and S. P. Vernekar, Journal of Polymer Science Part A: Polymer Chemistry, 2009, 47, 2289-2303.

121. J.-C. Chen, Y.-R. Hsiao, Y.-C. Liu, P.-Y. Chen and K.-H. Chen, Polymer, 2019, 182, 121814.

122. N. Xu, X. X. Guo, J. H. Fang, H. J. Xu and J. Yin, Journal of Polymer Science Part A: Polymer Chemistry, 2009, 47, 6992-7002.

123. M. Kulkarni, R. Potrekar, R. A. Kulkarni and S. P. Vernekar, Journal of Polymer Science Part a-Polymer Chemistry, 2008, 46, 5776-5793.

124. Y. S. Guan, H. T. Pu and D. C. Wan, Polymer Chemistry, 2011, 2, 1287-1292.

125. S. Angioni, P. P. Righetti, E. Quartarone, E. Dilena, P. Mustarelli and A. Magistris, International Journal of Hydrogen Energy, 2011, 36, 7174-7182.

126. S. W. Chuang and S. L. C. Hsu, Journal of Polymer Science Part A: Polymer Chemistry, 2006, 44, 4508-4513. 
127. J. Yang, Q. Li, L. N. Cleemann, J. O. Jensen, C. Pan, N. J. Bjerrum and R. He, Advanced Energy Materials, 2013, 3, 622-630.

128. R. P. Singh, X. Li, K. W. Dudeck, B. C. Benicewicz and K. A. Berchtold, Polymer, 2017 , 119, 134-141.

129. S. Kang, C. Zhang, G. Xiao, D. Yan and G. Sun, Journal of Membrane Science, 2009, 334, 91-100.

130. J. A. Mader and B. C. Benicewicz, Macromolecules, 2010, 43, 6706-6715.

131. N. N. Krishnan, H.-J. Lee, H.-J. Kim, J.-Y. Kim, I. Hwang, J. H. Jang, E. A. Cho, S.-K. Kim, D. Henkensmeier, S.-A. Hong and T.-H. Lim, European Polymer Journal, 2010, 46, 1633-1641.

132. J. A. Mader and B. C. Benicewicz, Fuel Cells, 2011, 11, 212-221.

133. N. Nambi Krishnan, A. Konovalova, D. Aili, Q. Li, H. S. Park, J. H. Jang, H.-J. Kim and D. Henkensmeier, Journal of Membrane Science, 2019, 588, 117218.

134. S. Maity and T. Jana, Macromolecules, 2013, 46, 6814-6823.

135. J. Peron, E. Ruiz, D. J. Jones and J. Roziere, Journal of Membrane Science, 2008, 314, 247-256.

136. J. Hu, J. Luo, P. Wagner, O. Conrad and C. Agert, Electrochemistry Communications, 2009, 11, 2324-2327.

137. H. Cho, E. Hur, D. Henkensmeier, G. Jeong, E. Cho, H. J. Kim, J. H. Jang, K. Y. Lee, H. A. Hjuler, Q. Li, J. O. Jensen and L. N. Cleemann, European Polymer Journal, 2014, 58, $135-143$.

138. H. Borjigin, K. A. Stevens, R. Liu, J. D. Moon, A. T. Shaver, S. Swinnea, B. D. Freeman, J. S. Riffle and J. E. McGrath, Polymer, 2015, 71, 135-142.

139. J. Jouanneau, R. Mercier, L. Gonon and G. Gebel, Macromolecules, 2007, 40, 983-990.

140. B. Sana, A. Das and T. Jana, Polymer, 2019, 172, 213-220.

141. J. A. Mader and B. C. Benicewicz, Fuel Cells, 2011, 11, 222-237.

142. S. Maity and T. Jana, ACS Applied Materials \& Interfaces, 2014, 6, 6851-6864.

143. H.-S. Lee, A. Roy, O. Lane and J. E. McGrath, Polymer, 2008, 49, 5387-5396.

144. F. Schonberger, G. Q. Qian and B. C. Benicewicz, Journal of Polymer Science Part aPolymer Chemistry, 2017, 55, 1831-1843. 
145. V. Kumar, S. Chatterjee, P. Sharma, S. Chakrabarty, C. V. Avadhani and S. Sivaram, Journal of Polymer Science Part a-Polymer Chemistry, 2018, 56, 1046-1057.

146. O. D. Thomas, T. J. Peckham, U. Thanganathan, Y. Yang and S. Holdcroft, Journal of Polymer Science Part A: Polymer Chemistry, 2010, 48, 3640-3650.

147. L. Sheng, H. Xu, X. Guo, J. Fang, L. Fang and J. Yin, Journal of Power Sources, 2011, 196, 3039-3047.

148. S. Qing, W. Huang and D. Yan, European Polymer Journal, 2005, 41, 1589-1595.

149. X. Li, C. Liu, S. Zhang, L. Zong and X. Jian, Journal of Membrane Science, 2013, 442, $160-167$.

150. X. Wang, S. Wang, C. Liu, J. S. Li, F. X. Liu, X. Tian, H. Chen, T. J. Mao, J. M. Xu and Z. Wang, Electrochimica Acta, 2018, 283, 691-698.

151. 2006.

152. D. C. Seel and B. C. Benicewicz, Journal of Membrane Science, 2012, 405-406, 57-67.

153. C. Liu, X. Li, J. Xu and X. Jian, European Polymer Journal, 2011, 47, 1852-1860.

154. X. Li, C. Liu, S. Zhang, G. Yu and X. Jian, Journal of Membrane Science, 2012, 423, 128135.

155. H. M. Ma, H. Zhu and Z. M. Wang, Journal of Polymer Science Part a-Polymer Chemistry, 2019, 57, 1087-1096.

156. S. K. Kim, T. H. Kim, J. W. Jung and J. C. Lee, Macromol. Mater. Eng., 2008, 293, 914921.

157. A. Sannigrahi, D. Arunbabu, R. M. Sankar and T. Jana, The Journal of Physical Chemistry $B, 2007,111,12124-12132$.

158. Z. Liang, X. Jiang, H. Xu, D. Chen and J. Yin, Macromolecular Chemistry and Physics, 2009, 210, 1632-1639.

159. D. Aili, I. Javakhishvili, J. Han, K. Jankova, C. Pan, S. Hvilsted, J. O. Jensen, N. J. Bjerrum and Q. Li, Macromolecular Chemistry and Physics, 2016, 217, 1161-1168.

160. P. M. Hergenrother, J. G. Smith and J. W. Connell, Polymer, 1993, 34, 856-865.

161. J. L. Wang, Y. L. Song, C. Zhang, Z. B. Ye, H. Liu, M. H. Lee, D. H. Wang and J. B. Ji, Macromolecular Chemistry and Physics, 2008, 209, 1495-1502.

162. J. G. Smith, J. W. Connell and P. M. Hergenrother, Journal of Polymer Science Part aPolymer Chemistry, 1993, 31, 3099-3108. 
163. B. Wang, Y. Tang, Z. Wen and H. Wang, European Polymer Journal, 2009, 45, 29622965.

164. M. Litt, R. Ameri, Y. Wang, R. Savinell and J. Wainright, in Solid State Ionics V, eds. G. A. Nazri, C. Julien and A. Rougier, Materials Research Society, Warrendale, 1999, vol. 548, pp. 313-323.

165. F. Viva, N. Heredia, S. P. Palmbaum, L. Diaz, J. De Diego, M. Lozano, M. Bruno and H. Corti, Journal of The Electrochemical Society, 2017, 164, F866-F872.

166. Y. Yuan, F. Johnson and I. Cabasso, Journal of Applied Polymer Science, 2009, 112, 34363441.

167. D. Aili, K. Jankova, Q. Li, N. J. Bjerrum and J. O. Jensen, Journal of Membrane Science, 2015, 492, 422-429.

168. T. Kojima, R. Yokota, M. Kochi and H. Kambe, Journal of Polymer Science Part BPolymer Physics, 1980, 18, 1673-1683.

169. A. Buckley, D. Stuetz and G. A. Serad, Journal, 1987, 11, 572-601.

170. S. Peng, X. Wu, X. Yan, L. Gao, Y. Zhu, D. Zhang, J. Li, Q. Wang and G. He, Journal of Materials Chemistry A, 2018, 6, 3895-3905.

171. C. B. Shogbon, J. L. Brousseau, H. F. Zhang, B. C. Benicewicz and Y. A. Akpalu, Macromolecules, 2006, 39, 9409-9418.

172. A. Sannigrahi, D. Arunbabu, R. M. Sankar and T. Jana, Macromolecules, 2007, 40, 28442851.

173. T. R. Hanley, T. E. Helminiak and C. L. Benner, Journal of Applied Polymer Science, 1978, 22, 2965-2978.

174. T. S. Chung and P. N. Chen, Journal of Applied Polymer Science, 1990, 40, 1209-1222.

175. T. S. Chung, Polym. Eng. Sci., 1994, 34, 428-433.

176. H. L. Lin, Y. C. Chen, C. C. Li, C. P. Cheng and T. L. Yu, Journal of Power Sources, 2008, 181, 228-236.

177. J. H. Liao, Q. F. Li, H. C. Rudbeck, J. O. Jensen, A. Chromik, N. J. Bjerrum, J. Kerres and W. Xing, Fuel Cells, 2011, 11, 745-755.

178. US 4579915, 1990.

179. I. Yamaguchi, K. Osakada and T. Yamamoto, Macromolecules, 1997, 30, 4288-4294.

180. H. T. Pu, Q. Z. Liu and G. H. Liu, Journal of Membrane Science, 2004, 241, 169-175. 
181. H. T. Pu and G. H. Liu, Polym. Int., 2005, 54, 175-179.

182. J. R. Klaehn, T. A. Luther, C. J. Orme, M. G. Jones, A. K. Wertsching and E. S. Peterson, Macromolecules, 2007, 40, 7487-7492.

183. S. C. Kumbharkar and U. K. Kharul, European Polymer Journal, 2009, 45, 3363-3371.

184. I. Yamaguchi, K. Osakada and T. Yamamoto, Macromolecules, 2000, 33, 2315-2319.

185. Y. Lee, S. Kim, A. Maljusch, O. Conradi, H.-J. Kim, J. H. Jang, J. Han, J. Kim and D. Henkensmeier, Polymer, 2019, 174, 210-217.

186. V. Sinigersky, D. Budurova, H. Penchev, F. Ublekov and I. Radev, Journal of Applied Polymer Science, 2013, 129, 1223-1231.

187. M. B. Gieselman and J. R. Reynolds, Macromolecules, 1992, 25, 4832-4834.

188. J. M. Bae, I. Honma, M. Murata, T. Yamamoto, M. Rikukawa and N. Ogata, Solid State Ionics, 2002, 147, 189-194.

189. H. Namazi and H. Ahmadi, Journal of Membrane Science, 2011, 383, 280-288.

190. H.-L. Lin, C.-R. Hu, S.-W. Lai and T. L. Yu, Journal of Membrane Science, 2012, 389, 399-406.

191. X. Glipa, M. El Haddad, D. J. Jones and J. Roziere, Solid State Ionics, 1997, 97, 323-331.

192. P. R. Sukumar, W. C. Wu, D. Markova, O. Unsal, M. Klapper and K. Mullen, Macromolecular Chemistry and Physics, 2007, 208, 2258-2267.

193. J. Yang, D. Aili, Q. Li, Y. Xu, P. Liu, Q. Che, J. O. Jensen, N. J. Bjerrum and R. He, Polymer Chemistry, 2013, 4, 4768-4775.

194. A. R. Hlil, S. Matsumura and A. S. Hay, Macromolecules, 2008, 41, 1912-1914.

195. Y. H. Qi, Y. Gao, S. H. Tian, A. R. Hlil, J. Gaudet, D. Guay and A. S. Hay, Journal of Polymer Science Part a-Polymer Chemistry, 2009, 47, 1920-1929.

196. Y. W. Xu, J. Tang, G. J. Chang, X. Luo, F. H. Zhu and L. Zhang, Asian J. Chem., 2013, 25, 4013-4016.

197. Y. Xu, J. Tang, G. Chang, F. Zhu, X. Luo and L. Zhang, Macromol. Res., 2013, 21, 681686.

198. Y. W. Xu, J. Tang, G. J. Chang, X. Luo, F. H. Zhu and L. Zhang, Polym. Int., 2013, 62, 791-796.

199. Y. W. Xu, X. W. Cui, F. H. Zhu, X. Luo, Q. Yin and L. Zhang, Polym. Int., 2014, 63, 537545. 
200. A. Kirkebæk, D. Aili, B. Yue, A. Vassiliev, L. N. Cleemann, J. O. Jensen and Q. Li, Fuel Cells, 2018, 0.

201. Q. Li, C. Pan, J. O. Jensen, P. Noyé and N. J. Bjerrum, Chemistry of Materials, 2007, 19, 350-352.

202. F. Mack, K. Aniol, C. Ellwein, J. Kerres and R. Zeis, Journal of Materials Chemistry A, 2015, 3, 10864-10874.

203. J. Yang, H. Jiang, L. Gao, J. Wang, Y. Xu and R. He, International Journal of Hydrogen Energy, 2018, 43, 3299-3307.

204. A. Naderi, A. Asadi Tashvigh and T.-S. Chung, Journal of Membrane Science, 2019, 572, 343-349.

205. P. Noyé, Q. Li, C. Pan and N. J. Bjerrum, Polymers for Advanced Technologies, 2008, 19, 1270-1275.

206. J. S. Yang, L. P. Gao, J. Wang, Y. X. Xu, C. Liu and R. H. He, Macromolecular Chemistry and Physics, 2017, 218, 10.

207. D. Aili, Q. Li, E. Christensen, J. O. Jensen and N. J. Bjerrum, Polym. Int., 2011, 60, $1201-$ 1207.

208. J. Kerres and V. Atanasov, International Journal of Hydrogen Energy, 2015, 40, 1472314735.

209. J. Yang, D. Aili, Q. Li, L. N. Cleemann, J. O. Jensen, N. J. Bjerrum and R. He, ChemSusChem, 2013, 6, 275-282.

210. C. Lin, J. Wang, G. Shen, J. Duan, D. Xie, F. Cheng, Y. Zhang and S. Zhang, Journal of Membrane Science, 2019, 590, 117303.

211. S. Wang, C. Zhao, W. Ma, N. Zhang, Z. Liu, G. Zhang and H. Na, Journal of Power Sources, 2013, 243, 102-109.

212. M. Han, G. Zhang, Z. Liu, S. Wang, M. Li, J. Zhu, H. Li, Y. Zhang, C. M. Lew and H. Na, Journal of Materials Chemistry, 2011, 21, 2187-2193.

213. S. Wang, C. Zhao, W. Ma, G. Zhang, Z. Liu, J. Ni, M. Li, N. Zhang and H. Na, Journal of Membrane Science, 2012, 411-412, 54-63.

214. H.-L. Lin, Y.-C. Chou, T. L. Yu and S.-W. Lai, International Journal of Hydrogen Energy, 2012, 37, 383-392. 
215. J. Yang, Y. Xu, P. Liu, L. Gao, Q. Che and R. He, Electrochimica Acta, 2015, 160, 281287.

216. P. Sun, Z. F. Li, S. W. Wang and X. Y. Yin, Journal of Membrane Science, 2018, 549, 660-669.

217. H. Luo, H. Pu, Z. Chang, D. Wan and H. Pan, Journal of Materials Chemistry, 2012, 22, 20696-20705.

218. D. Joseph, N. N. Krishnan, D. Henkensmeier, J. H. Jang, S. H. Choi, H.-J. Kim, J. Han and S. W. Nam, Journal of Materials Chemistry A, 2017, 5, 409-417.

219. S. K. Kim, S. W. Choi, W. S. Jeon, J. O. Park, T. Ko, H. Chang and J. C. Lee, Macromolecules, 2012, 45, 1438-1446.

220. S. K. Kim, K. H. Kim, J. O. Park, K. Kim, T. Ko, S. W. Choi, C. Pak, H. Chang and J. C. Lee, Journal of Power Sources, 2013, 226, 346-353.

221. S.-K. Kim, T. Ko, S.-W. Choi, J. O. Park, K.-H. Kim, C. Pak, H. Chang and J.-C. Lee, Journal of Materials Chemistry, 2012, 22, 7194-7205.

222. H.-Y. Li and Y.-L. Liu, Journal of Materials Chemistry A, 2013, 1, 1171-1178.

223. J. K. Gillham, Science, 1963, 139, 494-495.

224. D. Aili, L. N. Cleemann, Q. Li, J. O. Jensen, E. Christensen and N. J. Bjerrum, Journal of Materials Chemistry, 2012, 22, 5444-5453.

225. S. Lai, J. Park, S. Cho, M. Tsai, H. Lim and K. Chen, International Journal of Hydrogen Energy, 2016, 41, 9556-9562.

226. L. Wang, Z. Liu, Y. Liu and L. Wang, Journal of Membrane Science, 2019, 583, 110-117.

227. L. Leung, D. J. Williams, F. E. Karasz and W. J. Macknight, Polymer Bulletin, 1986, 16, 457-464.

228. G. Guerra, S. Choe, D. J. Williams, F. E. Karasz and W. J. MacKnight, Macromolecules, 1988, 21, 231-234.

229. S. Stankovic, G. Guerra, D. J. Williams, F. E. Karasz and W. J. Macknight, Polymer Communications, 1988, 29, 14-16.

230. G. Guerra, D. J. Williams, F. E. Karasz and W. J. Macknight, Journal of Polymer Science Part B-Polymer Physics, 1988, 26, 301-313.

231. K. M. Liang, G. Banhegyi, F. E. Karasz and W. J. Macknight, Journal of Polymer Science Part B-Polymer Physics, 1991, 29, 649-657. 
232. T.-S. Chung, W. F. Guo and Y. Liu, Journal of Membrane Science, 2006, 271, 221-231.

233. P. Musto, F. E. Karasz and W. J. MacKnight, Polymer, 1989, 30, 1012-1021.

234. T.-K. Ahn, M. Kim and S. Choe, Macromolecules, 1997, 30, 3369-3374.

235. E. Foldes, E. Fekete, F. E. Karasz and B. Pukanszky, Polymer, 2000, 41, 975-983.

236. P. Musto, F. E. Karasz and W. J. MacKnight, Macromolecules, 1991, 24, 4762-4769.

237. J. D. Moon, A. T. Bridge, C. D'Ambra, B. D. Freeman and D. R. Paul, Journal of Membrane Science, 2019, 582, 182-193.

238. H. Cherdron, M. Haubs, F. Herold, A. Schneller, O. Herrmann-Schonherr and R. Wagener, Journal of Applied Polymer Science, 1994, 53, 507-512.

239. F. Chen, X. Che, X. Ren, L. Zhao, D. Zhang, H. Chen, J. Liu and J. Yang, Journal of The Electrochemical Society, 2020, 167, 060511.

240. D. Arunbabu, A. Sannigrahi and T. Jana, The Journal of Physical Chemistry B, 2008, 112, 5305-5310.

241. Y. Wang, S. H. Goh and T.-S. Chung, Polymer, 2007, 48, 2901-2909.

242. P. Musto, L. Wu, F. E. Karasz and W. J. Macknight, Polymer, 1991, 32, 3-11.

243. L. A. Diaz, R. E. Coppola, G. C. Abuin, R. Escudero-Cid, D. Herranz and P. Ocón, Journal of Membrane Science, 2017, 535, 45-55.

244. J. Kerres, A. Ullrich, F. Meier and T. Haring, Solid State Ionics, 1999, 125, 243-249.

245. J. Kerres, A. Ullrich, T. Haring, M. Baldauf, U. Gebhardt and W. Preidel, Journal of New Materials for Electrochemical Systems, 2000, 3, 229-239.

246. V. Deimede, G. A. Voyiatzis, J. K. Kallitsis, Q. Li and N. J. Bjerrum, Macromolecules, 2000, 33, 7609-7617.

247. J. K. Lee and J. Kerres, Journal of Membrane Science, 2007, 294, 75-83.

248. J. Kerres, F. Schonberger, A. Chromik, T. Haring, Q. Li, J. O. Jensen, C. Pan, P. Noye and N. J. Bjerrum, Fuel Cells, 2008, 8, 175-187.

249. C. Seyb and J. Kerres, European Polymer Journal, 2013, 49, 518-531.

250. F. Schönberger, M. Hein and J. Kerres, Solid State Ionics, 2007, 178, 547-554.

251. O. Acar, U. Sen, A. Bozkurt and A. Ata, International Journal of Hydrogen Energy, 2009, 34, 2724-2730.

252. M. R. Berber, T. Fujigaya, K. Sasaki and N. Nakashima, Sci Rep, 2013, 3, 1-7.

253. M. R. Berber, T. Fujigaya and N. Nakashima, ChemCatChem, 2014, 6, 567-571. 
254. Y. Wang, S. N. Rashkeev, J. R. Klaehn, C. J. Orme and E. S. Peterson, Journal of Membrane Science, 2011, 384, 176-183.

255. E. Babcock, N. Szekely, A. Konovalova, Y. Lin, M. S. Appavou, G. Mangiapia, Z. Revay, C. Stieghorst, O. Holderer, D. Henkensmeier, W. Lehnert and M. Carmo, Journal of Membrane Science, 2019, 577, 12-19.

256. P. Musto, P. La Manna, J. D. Moon, M. Galizia and B. D. Freeman, ACS Omega, 2018, 3, 11592-11607.

257. N. W. Brooks, R. A. Duckett, J. Rose, I. M. Ward and J. Clements, Polymer, 1993, 34, 4038-4042.

258. Q. Li, R. H. He, R. W. Berg, H. A. Hjuler and N. J. Bjerrum, Solid State Ionics, 2004, 168, 177-185.

259. D. Aili, K. Jankova, J. Han, N. J. Bjerrum, J. O. Jensen and Q. Li, Polymer, 2016, 84, 304310.

260. Q. Li, J. O. Jensen, C. Pan, V. Bandur, M. S. Nilsson, F. Schonberger, A. Chromik, M. Hein, T. Haring, J. Kerres and N. J. Bjerrum, Fuel Cells, 2008, 8, 188-199.

261. P. Musto, F. E. Karasz and W. J. MacKnight, Polymer, 1993, 34, 2934-2945.

262. R. A. Gaudiana and R. T. Conley, Polymer Letters, 1969, 7, 793-801.

263. B. Z. Xing and O. Savadogo, Journal of New Materials for Electrochemical Systems, 1999, 2, 95-101.

264. R. Bouchet and E. Siebert, Solid State Ionics, 1999, 118, 287-299.

265. X. Glipa, B. Bonnet, B. Mula, D. J. Jones and J. Roziere, Journal of Materials Chemistry, 1999, 9, 3045-3049.

266. M. Kawahara, J. Morita, M. Rikukawa, K. Sanui and N. Ogata, Electrochimica Acta, 2000, 45, 1395-1398.

267. R. Bouchet, S. Miller, M. Duclot and J. L. Souquet, Solid State Ionics, 2001, 145, 69-78.

268. H. T. Pu, W. H. Meyer and G. Wegner, Journal of Polymer Science Part B: Polymer Physics, 2002, 40, 663-669.

269. R. He, Q. Che and B. Sun, Fibers Polym, 2008, 9, 679-684.

270. M. Sadeghi, H. Moadel, S. Khatti and B. Ghalei, Journal of Macromolecular Science, Part B: Physics, 2010, 49, 1128 - 1135. 
271. D. Aili, T. Allward, S. M. Alfaro, C. Hartmann-Thompson, T. Steenberg, H. A. Hjuler, Q. Li, J. O. Jensen and E. J. Stark, Electrochimica Acta, 2014, 140, 182-190.

272. A. Kannan, D. Aili, L. N. Cleemann, Q. Li and J. O. Jensen, International Journal of Hydrogen Energy, 2019, DOI: https://doi.org/10.1016/j.jhydene.2019.10.186.

273. N. N. Krishnan, D. Joseph, N. M. H. Duong, A. Konovalova, J. H. Jang, H.-J. Kim, S. W. Nam and D. Henkensmeier, Journal of Membrane Science, 2017, 544, 416-424.

274. Y. L. Ma, J. S. Wainright, M. H. Litt and R. F. Savinell, Journal of the Electrochemical Society, 2004, 151, A8-A16.

275. F. Conti, A. Majerus, V. Di Noto, C. Korte, W. Lehnert and D. Stolten, Phys. Chem. Chem. Phys., 2012, 14, 10022-10026.

276. G. A. Giffin, F. Conti, S. Lavina, A. Majerus, G. Pace, C. Korte, W. Lehnert and V. Di Noto, International Journal of Hydrogen Energy, 2014, 39, 2776-2784.

277. C. E. Hughes, S. Haufe, B. Angerstein, R. Kalim, U. Mahr, A. Reiche and M. Baldus, Journal of Physical Chemistry B, 2004, 108, 13626-13631.

278. J.-P. Melchior, G. Majer and K.-D. Kreuer, Phys. Chem. Chem. Phys., 2017, 19, 601-612.

279. R. H. He, Q. Li, J. O. Jensen and N. J. Bjerrum, Journal of Polymer Science Part A: Polymer Chemistry, 2007, 45, 2989-2997.

280. C. Korte, F. Conti, J. Wackerl, P. Dams, A. Majerus and W. Lehnert, Journal of Applied Electrochemistry, 2015, 45, 857-871.

281. F. Conti, F. Bertasi, J. Wackerl, P. Dams, V. Di Noto, W. Lehnert and C. Korte, ECS Transactions, 2016, 72, 157-167.

282. J. Liao, J. Yang, Q. Li, L. N. Cleemann, J. O. Jensen, N. J. Bjerrum, R. He and W. Xing, Journal of Power Sources, 2013, 238, 516-522.

283. S. M. Dockheer, L. Gubler, A. Wokaun and W. H. Koppenol, Phys. Chem. Chem. Phys., 2011, 13, 12429-12434.

284. G. M. Zhang, X. X. Guo, J. H. Fang, K. C. Chen and K. I. Okamoto, Journal of Membrane Science, 2009, 326, 708-713.

285. M. A. Molleo, X. Chen, H. J. Ploehn, K. J. Fishel and B. C. Benicewicz, Fuel Cells, 2014, 14, 16-25.

286. D. Mecerreyes, H. Grande, O. Miguel, E. Ochoteco, R. Marcilla and I. Cantero, Chemistry of Materials, 2004, 16, 604-607. 
287. J. Weber, M. Antonietti and A. Thomas, Macromolecules, 2007, 40, 1299-1304.

288. A. K. Perry, L. K. More, E. Andrew Payzant, R. A. Meisner, B. G. Sumpter and B. C. Benicewicz, Journal of Polymer Science Part B: Polymer Physics, 2014, 52, 26-35.

289. Q. Li, H. A. Hjuler and N. J. Bjerrum, Journal of Applied Electrochemistry, 2001, 31, 773779.

290. J. R. P. Jayakody, S. H. Chung, L. Durantino, H. Zhang, L. Xiao, B. C. Benicewicz and S. G. Greenbaum, Journal of the Electrochemical Society, 2007, 154, B242-B246.

291. G. A. Giffin, S. Galbiati, M. Walter, K. Aniol, C. Ellwein, J. Kerres and R. Zeis, Journal of Membrane Science, 2017, 535, 122-131.

292. K.-D. Kreuer, Chemistry of Materials, 2014, 26, 361-380.

293. T. Dippel, K. D. Kreuer, J. C. Lassègues and D. Rodriguez, Solid State Ionics, 1993, 61, 41-46.

294. S. Suarez, N. Kodiweera, P. Stallworth, S. Yu, S. G. Greenbaum and B. C. Benicewicz, Journal of Physical Chemistry B, 2012, 116, 12545-12551.

295. Y. Aihara, A. Sonai, M. Hattori and K. Hayamizu, Journal of Physical Chemistry B, 2006, 110, 24999-25006.

296. J.-P. Melchior, K.-D. Kreuer and J. Maier, Phys. Chem. Chem. Phys., 2017, 19, 587-600.

297. T. Arlt, W. Maier, C. Tötzke, C. Wannek, H. Markötter, F. Wieder, J. Banhart, W. Lehnert and I. Manke, Journal of Power Sources, 2014, 246, 290-298.

298. S. H. Eberhardt, M. Toulec, F. Marone, M. Stampanoni, F. N. Büchi and T. J. Schmidt, Journal of the Electrochemical Society, 2015, 162, F310-F316.

299. S. H. Eberhardt, F. Marone, M. Stampanoni, F. N. Buchi and T. J. Schmidt, Journal of the Electrochemical Society, 2016, 163, F842-F847.

300. H. Becker, L. N. Cleemann, D. Aili, J. O. Jensen and Q. Li, Electrochemistry Communications, 2017, 82, 21-24.

301. H. Becker, U. Reimer, D. Aili, L. N. Cleemann, J. O. Jensen, W. Lehnert and Q. Li, Journal of The Electrochemical Society, 2018, 165, F863-F869.

302. T. Søndergaard, L. N. Cleemann, H. Becker, T. Steenberg, H. A. Hjuler, L. Seerup, Q. Li and J. O. Jensen, Journal of The Electrochemical Society, 2018, 165, F3053-F3062.

303. K. Shirata and S. Kawauchi, The Journal of Physical Chemistry B, 2015, 119, 592-603. 
304. D. Aili, J. Zhang, M. T. Dalsgaard Jakobsen, H. Zhu, T. Yang, J. Liu, M. Forsyth, C. Pan, J. O. Jensen, L. N. Cleemann, S. P. Jiang and Q. Li, Journal of Materials Chemistry A, 2016, 4, 4019-4024.

305. Y. Cheng, J. Zhang, S. Lu, H. Kuang, J. Bradley, R. De Marco, D. Aili, Q. Li, C. Q. Cui and S. P. Jiang, International Journal of Hydrogen Energy, 2018, 43, 22487-22499.

306. A. Kannan, D. Aili, L. N. Cleemann, Q. Li and J. O. Jensen, International Journal of Hydrogen Energy, 2020, 45, 1008-1017.

307. M. Hu, E. M. Pearce and T. K. Kwei, Journal of Polymer Science Part A: Polymer Chemistry, 1993, 31, 553-561.

308. D. Henkensmeier, H. J. Kim, H. J. Lee, D. H. Lee, I. H. Oh, S. A. Hong, S. W. Nam and T. H. Lim, Macromol. Mater. Eng., 2011, 296, 899-908.

309. O. D. Thomas, K. J. W. Y. Soo, T. J. Peckham, M. P. Kulkarni and S. Holdcroft, Polymer Chemistry, 2011, 2, 1641-1643.

310. Z. J. Chang, D. Henkensmeier and R. Y. Chen, Chemsuschem, 2017, 10, 3193-3197.

311. D. Henkensmeier, H. Cho, M. Brela, A. Michalak, A. Dyck, W. Germer, N. M. H. Duong, J. H. Jang, H.-J. Kim, N.-S. Woo and T.-H. Lim, International Journal of Hydrogen Energy, 2014, 39, 2842-2853.

312. H.-J. Lee, J. Choi, J. Y. Han, H.-J. Kim, Y.-E. Sung, H. Kim, D. Henkensmeier, E. Ae Cho, J. H. Jang and S. J. Yoo, Polymer Bulletin, 2013, 70, 2619-2631.

313. J. Y. Lee, D.-H. Lim, J. E. Chae, J. Choi, B. H. Kim, S. Y. Lee, C. W. Yoon, S. Y. Nam, J. H. Jang, D. Henkensmeier, S. J. Yoo, J.-Y. Kim, H.-J. Kim and H. C. Ham, Journal of Membrane Science, 2016, 514, 398-406.

314. A. G. Wright, T. Weissbach and S. Holdcroft, Angewandte Chemie-International Edition, 2016, 55, 4818-4821.

315. N. Ziv and D. R. Dekel, Electrochemistry Communications, 2018, 88, 109-113.

316. M. Mokhtari, M. J. Eslamibidgoli and M. H. Eikerling, ACS Omega, 2020, 5, 1472-1478.

317. S. Holdcroft and J. Fan, Current Opinion in Electrochemistry, 2019, 18, 99-105.

318. H. Walba and R. W. Isensee, Journal of Organic Chemistry, 1961, 26, 2789-\&.

319. L. Zeng, T. S. Zhao, L. An, G. Zhao and X. H. Yan, Journal of Membrane Science, 2015, 493, 340-348.

320. R. N. Couto and J. J. Linares, Journal of Membrane Science, 2015, 486, 239-247. 
321. A. Konovalova, H. Kim, S. Kim, A. Lim, H. S. Park, M. R. Kraglund, D. Aili, J. H. Jang, H.-J. Kim and D. Henkensmeier, Journal of Membrane Science, 2018, 564, 653-662.

322. M. R. Kraglund, D. Aili, K. Jankova, E. Christensen, Q. Li and J. O. Jensen, Journal of the Electrochemical Society, 2016, 163, F3125-F3131.

323. H. Penchev, F. Ublekov, D. Budurova and V. Sinigersky, Mater. Lett., 2017, 187, 89-93.

324. H. Luo, G. Vaivars, B. Agboola, s. Mu and M. Mathe, Solid State Ionics, 2012, 208, 5255.

325. L. An, T. S. Zhao, Q. X. Wu and L. Zeng, International Journal of Hydrogen Energy, 2012, 37, 14536-14542.

326. J. Rozière, D. J. Jones, M. Marrony, X. Glipa and B. Mula, Solid State Ionics, 2001, 145, 61-68. 